Pontifícia UniVERsidade CATÓLICA do RIO DE JANEIRO

Análise dos ETFs para investidores: alternativas de carteiras de investimentos já diversificadas

\author{
Bianca Manela Pereira Lima
}

Trabalho de Conclusão de Curso

Centro de Ciências sociaIs - CCS

Departamento de AdMinistração

Graduação em Administração de Empresas 
Bianca Manela Pereira Lima

\section{Análise dos ETFs para investidores: alternativas de carteiras de investimentos já diversificadas}

Trabalho de Conclusão de Curso

Trabalho de Conclusão de Curso, apresentada ao programa de graduação em Administração da PUC-Rio como requisito parcial para a obtenção do título de graduação em Administração.

Orientador: Graziela Fortunato

Rio de Janeiro, junho de 2021 


\section{Agradecimentos}

Aos meus pais Orlando e Patricia e minhas irmãs Alessandra e Daniela, que sempre me incentivaram e me deram todo o apoio nas minhas decisões, me ajudando a chegar aonde estou hoje.

À minha orientadora Graziela Fortunato pelo suporte, paciência e tempo dedicado a me orientar na elaboração do Trabalho de Conclusão de Curso, me ajudando a chegar mais longe. Agradeço também aos professores do IAG - PUC-Rio pelo crescimento que proporcionaram, pelo incentivo ao meu desenvolvimento durante toda a graduação. 


\section{Resumo}

Manela Pereira Lima, Bianca. Fortunato, Graziela. Análise dos ETFs para investidores: alternativas de carteiras de investimentos já diversificadas. Rio de Janeiro, 2021. 40 p. Trabalho de Conclusão de Curso - Departamento de Administração. Pontifícia Universidade Católica do Rio de Janeiro.

É inegável o aumento do número de investidores no mercado de capitais nos últimos meses e, com isso, muitos deles são inexperientes. Além disso, a população brasileira carece de educação financeira, fazendo com que os investidores entrantes no mercado de capitais corram o risco de fazer uma alocação ineficiente ou equivocada de seus recursos. Dessa forma, este trabalho tem como objetivo analisar os fundos de índices, também conhecidos como ETFs como alternativa de investimento para investidores considerando-os carteiras já diversificadas. A teoria por trás da abordagem no trabalho se dá pelo cálculo de risco e rentabilidade e índice de Sharpe de ativos selecionados. Com base nestas informações são comparadas as variáveis em questão para que haja uma visão mais aprofundada e quantitativa sobre a alocação de recursos nos Exchange Traded Funds.

Palavras- chave: Investimentos; Exchange Traded Funds; Diversificação; Perfil de investidor; Renda variável; Risco; Retorno; Índice de Sharpe. 


\section{Abstract}

Manela Pereira Lima, Bianca. Fortunato, Graziela. Analysis of ETFs for investors: alternatives for already diversified investment portfolios. Rio de Janeiro, 2021. 40 p. Trabalho de Conclusão de Curso - Departamento de Administração. Pontifícia Universidade Católica do Rio de Janeiro.

The increase in the number of investors in the capital market in recent months is undeniable and, as a result, many of them are inexperienced. In addition, the Brazilian population lacks financial education, causing investors entering the capital market to run the risk of inefficient or wrong allocation of their resources. Thus, this work aims to analyze exchange traded funds, also known as ETFs as an investment alternative for investors considering them as already diversified portfolios. The theory behind the approach at work is based on the calculation of risk and return and Sharpe ratio of selected assets. Based on this information, the variables in question are compared so that there is a more in-depth and quantitative view of the allocation of resources in Exchange Traded Funds.

Keywords: Investments; Exchange Traded Funds; Diversification; Investor profile; Variable income; Risk; Return; Sharpe's Index. 


\section{Sumário}

1. Introdução

1.2.1. Objetivos intermediários do estudo

2. Referencial Teórico
1.2. Objetivo do estudo

71.1. Contexto e problema de estudo

92.1. O Tripé dos Investimentos

2.2. Perfil de investidor

2.3. Diversificação

2.4. O Comportamento financeiro dos investidores brasileiros

2.5. O cenário macroeconômico do Brasil em 2020

2.5.1. A Taxa Selic

2.5.2. O mercado de renda variável

2.5.3. Exchange Traded Funds

2.5.4. Relação Risco x Retorno

2.5.4.1. Rentabilidade

2.5.4.2. Risco

2.5.4.3. Índice de Sharpe

3.1. Tipo de pesquisa

\section{Análise dos resultados}

234.1. Descrição da amostra

4.2. Descrição e análise dos resultados

\section{Conclusão}

266 Referências Bibliográficas 27Anexo

31Anexo I

Anexo II 34

Anexo III 


\section{Introdução}

\subsection{Contexto e problema de estudo}

Os investimentos financeiros têm papel fundamental na busca por maior tranquilidade financeira, independente da situação em que as pessoas se encontram. Investir o próprio dinheiro deve ser uma prática presente na vida das pessoas nas mais diversas situações financeiras, desde possíveis dívidas até pessoas que visam alcançar metas financeiras no médio ou longo prazo. Segundo Bona (2018), algumas das motivações para que as pessoas comecem a investir incluem: nova fonte de renda; proteção contra a inflação e preocupação com a aposentadoria.

Investimento financeiro, segundo Congo (2019), pode ser definido pela alocação de recursos, em busca de rendimentos futuros. Esses investimentos podem se dar em diferentes classes de ativos dentro do mercado, como por exemplo certificado de depósito bancário, também conhecidos como CDBs; ações; imóveis; moedas; fundos de investimentos; entre outros. A maneira com que cada investidor fará a alocação desses recursos varia de acordo com o perfil de investidor de cada um, e este leva em conta diversos fatores, tendo como principal a relação entre risco, rentabilidade e liquidez para seus objetivos, de acordo com Fayh (2020).

Segundo D’Ávila (2019), o brasileiro historicamente desenvolveu um comportamento avesso a grandes riscos, e isto se deu devido a diferentes situações presenciadas ao longo do tempo, como períodos de inflação significativa e confisco da poupança, no governo Collor em 1990. Como resultado, somado ao fato de a taxa de juros até 2017 ser superior a $10 \%$ ao ano, até 2018 é notável o comportamento do investidor brasileiro priorizando a segurança na escolha de seus investimentos. Como consequência, de acordo com D’Ávila (2019), a caderneta de poupança, por exemplo, ficou por bastante tempo como produto financeiro de grande apreço pelos investidores brasileiros, mesmo não sendo um ativo tão rentável quanto outras classes, e estes mantiveram seus investimentos por diferentes razões, como inércia ou simplicidade. 
Segundo Laporta (2020), contudo, no ano de 2020 houve um crescimento considerável do número de pessoas físicas ingressando na bolsa de valores, ultrapassando 3 milhões de CPFs cadastrados em 2020, com um aumento de 1,3 milhão de registros. Este dado mostra que, apesar da busca pela segurança do brasileiro até então, existe um potencial de crescimento do número de investidores no mercado de renda variável. Entretanto, com tantos investidores novos presentes no mercado de renda variável, grande parte destes não possui experiência para fazer as alocações mais eficazes ou usar as estratégias mais adequadas para seus objetivos.

De acordo com D'Ávila (2019), o primeiro grande crescimento no número de CPFs cadastrados na bolsa de valores foi em 2016, quando houve uma valorização de $40 \%$ do lbovespa, seguido de novas altas em 2017 e 2018, o que chamou a atenção dos investidores brasileiros. Nenhum desses dados, entretanto, é comparável à proporção do crescimento no ano de 2020. Isso indica que nesse contexto há uma quantidade expressiva de investidores novatos e inexperientes no mercado de renda variável no Brasil. Com isso, o processo decisório na escolha dos ativos para as carteiras desses investidores é um ponto delicado e que deve ser analisado.

Em paralelo a isso, segundo Borges (2012), os Exchange Traded Funds, também conhecidos como ETFs ou fundos de índices, são investimentos que possibilitam grande diversificação, economia e facilidade de negociação, além de uma baixa taxa administrativa, se comparada aos fundos de investimentos de gestão ativa. Dessa forma, a pesquisa busca promover uma visão mais aprofundada sobre os ETFs, sua estruturação e a possibilidade deste viabilizar o ingresso de tantos investidores no mercado de capitais, além de compreender o seguinte questionamento:

Os Exchange Traded Funds são boas alternativas em busca de alocação eficaz de recursos para investidores inexperientes? Se sim, quais são as características que os transformam em boas oportunidades para investidores entrantes no mercado de capitais?

\subsection{Objetivo do estudo}

O estudo visa mostrar de maneira mais consistente que os Exchange Traded Funds são carteiras diversificadas, onde o risco pode ser mais baixo do que os ativos individualmente, podendo ser uma alternativa para investidor inexperiente que tende a 
negligenciar tal variável. O projeto se dará através da identificação e análise dos dados históricos de diferentes ativos de renda variável, bem como indicadores de risco e retorno.

\subsubsection{Objetivos intermediários do estudo}

Para que seja possível alcançar o objetivo final proposto na pesquisa, é necessário passar por etapas de pesquisas, observações e análises. Portanto, os objetivos intermediários são:

- Analisar os principais ETFs da bolsa de valores brasileira, suas classificações e dados históricos. O presente estudo terá seu direcionamento referenciado no principal ETF da bolsa brasileira, o BOVA11;

- Cálculo e análise de rentabilidade e volatilidade entre os anos 2013 e 2021;

- Comparar as métricas obtidas sobre o BOVA11 e ações selecionadas que estão presentes na carteira teórica do lbovespa;

- Identificar as oportunidades presentes nos fundos de índices e a proporção dos investimentos em renda variável em relação ao perfil de investidor.

\section{Referencial Teórico}

\subsection{O Tripé dos Investimentos}

Qualquer investidor, no momento de estruturar a alocação de seu patrimônio, deve considerar três pilares fundamentais para os investimentos, conhecidos também como "o Tripé dos investimentos". Segundo Pinto (2020), esses pilares são: segurança, rentabilidade e liquidez. O investimento ideal levaria os três pilares em consideração, entretanto, não é possível encontrar um investimento que seja totalmente seguro, com liquidez imediata e rentabilidade excepcional. 
Segundo Fogaça (2020), liquidez está relacionada com a facilidade e rapidez com que um ativo pode ser transformado em dinheiro pelo seu preço justo no momento desejado. Dessa forma, quando um ativo possui alta liquidez, significa que no momento em que o investidor decide resgatá-lo, consegue fazê-lo com rapidez. Já o conceito de risco tem relação com incertezas, de acordo com Fogaça (2020). O risco no investimento é definido pelas incertezas e pela expectativa de que o retorno pode ser maior, menor ou até mesmo nulo ao longo do tempo. Por fim, a rentabilidade se refere ao retorno que cada ativo proporciona em determinado período de tempo.

De acordo com Pinto (2020), levando em consideração estes pilares e, avaliando no caso de cada investidor, seguindo seu perfil de investidor e seus objetivos, será possível entender os ativos e modelar uma estratégia adequada de investimentos. Considerando diferentes objetivos, o investidor consegue identificar qual o período de tempo que ele pode deixar o recurso alocado, o que indicará a necessidade de maior ou menor liquidez.

Existe a relação entre os três pilares, de modo que não seja possível encontrar os três, isto é, "quanto maior a possibilidade de retorno, maior tende a ser o risco do investimento", ao mesmo tempo que "se a liquidez é alta, a rentabilidade tende a ser baixa" de acordo com Fogaça (2020).

Esta relação é fundamental, visto que o investidor, em busca da melhor decisão possível em relação a seus investimentos, deve levar em consideração esses fatores, além de relacionar a seu perfil de investidor diante do mercado.

\subsection{Perfil de investidor}

Conforme o Tripé de investimentos indica, os três pilares dos investimentos são extremamente importantes para que o investidor possa tomar decisões sobre seus investimentos. Entretanto, além disso, é fundamental que o investidor saiba qual é o seu perfil para que possa fazer investimentos que estejam alinhados com seus objetivos e sua tolerância ao risco, isto é, o máximo de incerteza aceitável pelo investidor em relação a seus investimentos.

Segundo Rambo (2014), a grande necessidade de conhecimento em relação ao perfil de investidor está relacionada à percepção sobre apetite a risco, quanto espera de 
retorno para seus investimentos e valores que aceitaria perder em busca dessa rentabilidade. Portanto, conforme Rambo (2014) indica, uma vez que o investidor compreende seu perfil, consegue tomar melhores decisões para seus investimentos, levando em consideração suas perspectivas e evitando decepção diante de investimentos desenquadrados para seu perfil. De acordo com Rambo (2014), para que possa ser definido o perfil do investidor, deve-se abordar aspectos como a tolerância ao risco, objetivos dos investimentos, horizonte de tempo e nível de experiência.

Segundo Rambo (2014), o perfil de investidor pode ser dividido em três classificações principais. São eles: conservador; moderado e arrojado. A diferença entre eles se dá principalmente pelo nível de aversão ao risco, quão dispostos os investidores estão diante do risco em seus investimentos e é indicada com base nos conceitos explicados por Rambo (2014).

- Conservador - O investidor com perfil conservador busca a segurança como prioridade nas suas decisões de investimentos. É uma pessoa com grande aversão ao risco, ou seja, pouca tolerância e busca principalmente pela segurança de seu capital investido. Este perfil dá preferência à alocação de seu patrimônio, em grande parte, em ativos de baixo risco, investimentos que dão mais certeza do retorno ao longo do tempo, mesmo que proporcionem uma rentabilidade não tão atrativa. Com isso, a maior parte de seus investimentos são feitos em ativos mais seguros, como LCI - Letra de crédito imobiliário, títulos públicos, CDB - Certificado de Depósito Bancário, poupança, dentre outros ativos de renda fixa. Devido a sua aversão ao risco, investimentos mais voláteis e arriscados são desenquadrados para este perfil e, caso o investidor invista parte de seu patrimônio em ativos de renda variável, este normalmente se dará em proporções mais baixas.

- Moderado - O investidor com perfil moderado, também quer garantir a segurança e preservação de seu patrimônio, porém traz uma abertura maior a investimentos um pouco mais arriscados, que podem promover uma rentabilidade mais atrativa no médio e longo prazo. Os investidores moderados trazem maior equilíbrio entre a busca pela segurança e maiores retornos. Com isso, uma boa estratégia se dá pela diversificação de recursos, visto que o investidor manterá sua busca por retornos acima da média, sem que traga grandes riscos a seu patrimônio. Dessa forma, a alocação de recursos tende a ter uma porcentagem um pouco mais equilibrada entre ativos mais conservadores e arrojados. 
- Arrojado - O investidor com perfil arrojado é aquele que busca ganhos acima da média e tem uma tolerância ao risco maior do que os outros perfis. Este investidor está mais confortável diante do risco que está exposto e possui maior disponibilidade a possíveis perdas. A alocação de recursos de um investidor arrojado promove um valor mais baixo ou até mesmo nulo de ativos mais seguros como ativos de renda fixa e inclui a maior parte do patrimônio em ativos de renda variável, como ações e fundos imobiliários.

A Tabela 1, desenvolvida por Cardozo (2019), ilustra um comparativo em relação aos tipos de investimento para que diferentes perfis de investidores estejam alinhados com a decisão financeira a ser feita.

\section{Tabela 1 - Características dos investimentos em renda fixa e renda variável}

\begin{tabular}{ll}
\hline Renda Fixa & Renda Variável \\
\hline Mais seguro & Mais arriscado \\
\hline Rentabilidade menor & Rentabilidade maior \\
\hline Com garantias & Sem garantias \\
\hline Maior parcela do portfólio & Menor parcela do portfólio \\
\hline Empréstimo & Sociedade/Propriedade \\
\hline Tesouro Direto, CDB, LCl, etc. & Ações, moedas, etc. \\
\hline
\end{tabular}

Fonte: Cardozo (2019)

\subsection{Diversificação}

Apesar das classificações de perfis de risco frente às alternativas de investimentos, muitos investidores optam por reduzir exposição ao risco específico diante da volatilidade do mercado através da estratégia de diversificação. Segundo Matsumoto (2016), a Teoria da Carteira desenvolvida por Harry Markowitz traz a proposta de maximização do retorno e redução de risco através da chamada diversificação eficiente dos ativos, que busca minimizar o risco não sistemático da carteira dos investidores.

A teoria indica possibilidade para que investidores possam amenizar o possível impacto de riscos específicos, isto é, que são influenciados por fatores específicos daquele ativo. Já o risco sistemático, de acordo com Matsumoto (2016), é atingido por fatores que não são específicos, e sim macroeconômicos, como câmbio ou taxa de juros. A estratégia 
proposta por Markowitz busca otimizar a formação de carteiras dos investidores de modo que possam amenizar riscos de uma empresa ou setor específico.

Uma vez definido o perfil do investidor e os pilares dos investimentos, será possível analisar o cenário brasileiro dentro do contexto do mercado de capitais com maior profundidade, a fim de avaliar os Exchange Traded Funds como oportunidade para investidores de perfil agressivo que buscam diversificar carteiras no mercado de capitais mas não possuem conhecimento ou experiência ou tempo suficiente para acompanhamento.

\subsection{O Comportamento financeiro dos investidores brasileiros}

O brasileiro apresenta um número pequeno de investidores ainda, segundo Cardozo (2019). De acordo com a autora, há diversos fatores que geraram este cenário, desde suas condições financeiras, até questões mais profundas como insegurança frente à instabilidade política e econômica no Brasil, além da falta de estímulo à educação financeira no país.

Segundo Cardozo (2019), o brasileiro teria um perfil conservador, com um viés de decisões mais voltadas para a segurança em detrimento da rentabilidade. Entretanto, ao contrário do que foi apresentado pela autora, no ano de 2020 houve um crescimento significativo no número de investidores, com destaque ao mercado de renda variável.

De acordo com Bertão (2020), ao compararmos com o número de pessoas físicas com contas abertas na bolsa de valores brasileira, verificamos que houve, desde dezembro de 2019 , um crescimento de aproximadamente $76 \%$. Dessa forma, fica nítida a mudança no comportamento do investidor brasileiro, questionando assim se o perfil é efetivamente conservador. De fato, devido aos fatores explicitados anteriormente, como a insegurança e falta de estímulo à educação financeira, o número de investidores brasileiros ainda é baixo em comparação com a população total. Além disso, devido ao grande aumento recente de investidores neste mercado, pode-se notar que muitos dos participantes são inexperientes e iniciam suas operações no mercado de renda variável.

Figura 1: Comparativo entre o número de investidores na bolsa de valores brasileira em relação a população brasileira total. 


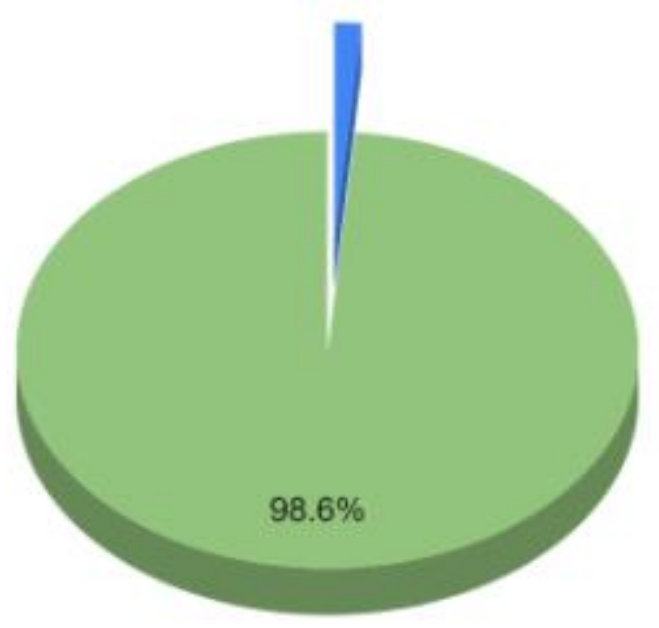

Nümero de CPFs cadastrados na bolsa

Nümero de Brasileiros

Fonte: Desenvolvida pelo aluno, com base em dados do IBGE.

Conforme a Figura 1 indica, ainda existe um potencial de crescimento considerável em relação ao mercado de renda variável, porém a evolução entre o final de 2019 e 2020 com aumento de $76 \%$ mostra que já houve grande movimento de migração dos brasileiros para o mercado de capitais. Além disso, vale lembrar que, segundo Cardozo (2019), até o ano de 2019, em uma pesquisa feita diante do público brasileiro, teve-se como resultado que $41,82 \%$ dos brasileiros investem seu dinheiro em produtos financeiros. Portanto, grande parte da população brasileira já está inserida neste cenário e o movimento do ano de 2020 tem sido em relação ao mercado de capitais.

Para compreensão com maior profundidade sobre este movimento, deve-se entender mais sobre o contexto macroeconômico do Brasil em 2020.

\subsection{O cenário macroeconômico do Brasil em 2020}

Dentre os mais diversos acontecimentos ao longo do ano de 2020 , o mais impactante no cenário global foi a pandemia COVID-19 e essa trouxe diferentes consequências econômicas para o mundo, e para o Brasil não foi diferente. De acordo com 
Júnior (2020), a pandemia do COVID-19 gerou uma grande redução das atividades econômicas no começo da crise - entre os meses de março e abril - e a atividade econômica iniciou sua retomada em maio.

Com a redução das atividades econômicas, houve um grande aumento do desemprego no Brasil. Apesar da taxa de desemprego já estar em constante crescimento desde 2014, em 2020 houve um aumento de 13,5 milhões de pessoas desempregadas durante o período da pandemia do COVID-19. Dessa forma, a taxa de desemprego teve aumento expressivo e ficou em 14\%, segundo Silveira (2020), resultando na redução da atividade econômica no Brasil e consequentemente no consumo por parte das famílias.

\subsubsection{A Taxa Selic}

Segundo Goldfajn (2002), o Banco Central do Brasil é a instituição cujo objetivo é garantir a estabilidade dos preços e o crescimento econômico e seu principal instrumento é a política monetária. O Banco Central controla os instrumentos de política monetária visando direcionar a economia. O instrumento mais importante e utilizado de política monetária é a Taxa Selic - Sistema Especial de Liquidação e de Custódia, definida periodicamente pelo COPOM.

A Taxa Selic é, segundo Miozzo (2020), é a taxa básica de juros da economia brasileira. Também conhecida como "taxa mãe", a Selic influencia todas as taxas de juros do Brasil, desde empréstimos até rentabilidade em aplicações de renda fixa.

De acordo com Salvalágio (2006), em contextos de instabilidade, como foi o ano de 2020, fica evidente a responsabilidade do Banco Central e das respectivas políticas monetárias, com a busca pela estabilidade dos preços. Diante disso, uma vez que houve um processo de redução da taxa de juros, a atividade econômica é estimulada. Dessa forma, com o objetivo de reestruturar a economia do Brasil após a recessão causada, dentre outros fatores, pelo COVID-19 no ano de 2020, houve significativas mudanças na Taxa Selic ao longo do ano.

Figura 2: Evolução da Taxa Selic (\% a.a.) ao longo dos anos. 


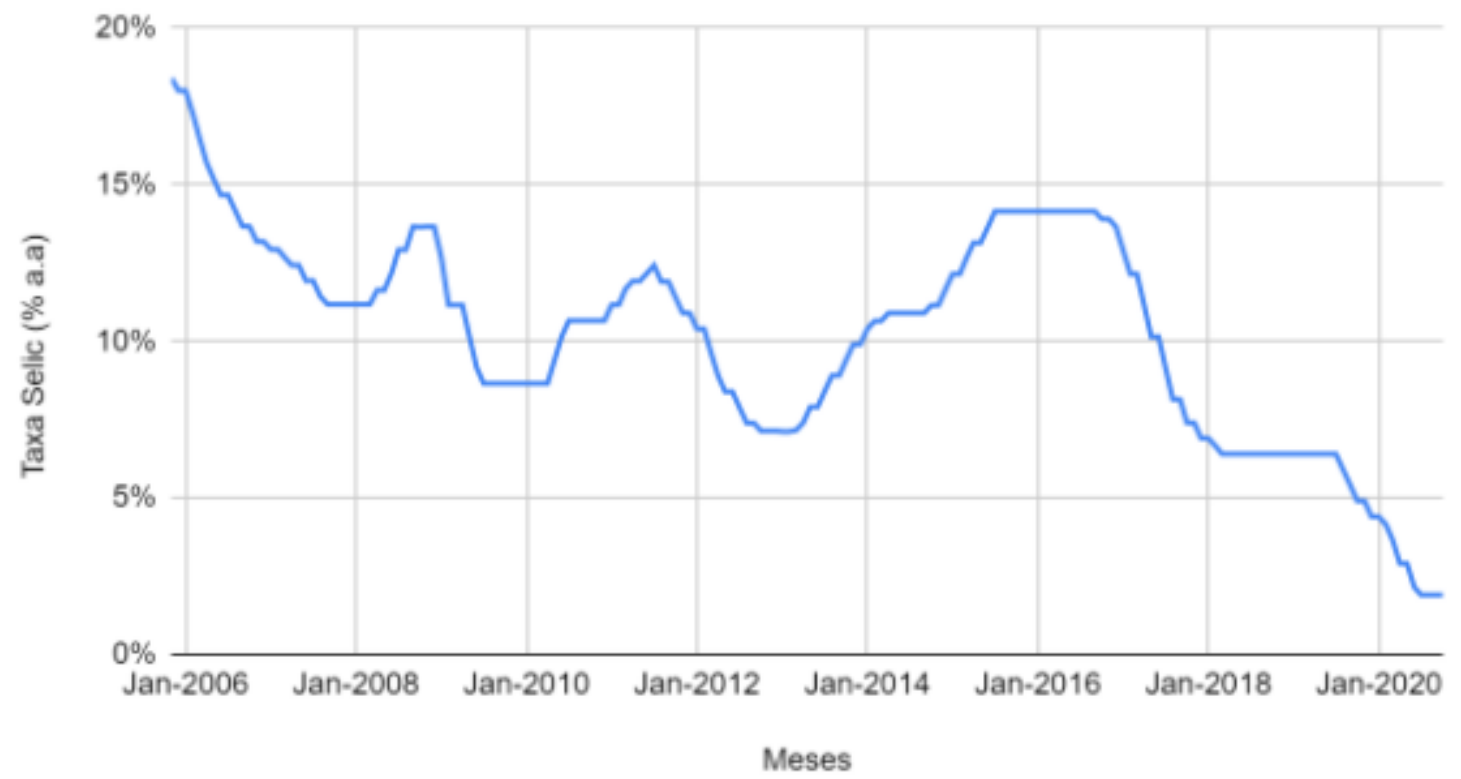

Fonte: Gráfico desenvolvido pelo aluno, com base em dados do Banco Central do Brasil.

Com base na Figura 2, é evidente que já existia este movimento de redução da taxa Selic devido a diversos fatores que envolviam a economia brasileira. Entretanto, é importante ressaltar uma redução mais expressiva e acelerada no ano de 2020. Uma forma de ilustrar esta queda é através do contraste de seu valor, uma vez que a Taxa permaneceu acima de 10\% ao ano até 2007 e em outubro de 2020 a Taxa Selic estava estabelecida em $2 \%$ ao ano.

Apesar de este ter a finalidade de estimular a economia brasileira, o investidor se vê em uma situação na qual precisa rever a alocação de sua carteira de investimentos. Vale lembrar que a Taxa Selic impacta diretamente diversos investimentos financeiros, sendo eles, de forma direta, os ativos de renda fixa, uma vez que seguem a Taxa Selic como referência.

Dessa forma, antes das reduções contínuas da taxa Selic, tendo como referência valores mais altos há alguns anos como por exemplo 17\% ao ano, os ativos de renda fixa eram considerados ativos bastante atrativos. Isso porque os ativos mantinham a segurança da renda fixa - devido a previsibilidade de seu retorno, além de incluir uma garantia a mais de segurança, o Fundo Garantidor de Crédito - e ofereciam uma rentabilidade excelente. Tal rentabilidade, se comparada ao mercado de renda variável, não compensaria o risco. 
Apesar da bolsa de valores no mesmo contexto oferecer um potencial retorno maior, por exemplo, naquele contexto, ainda assim os investimentos mais seguros traziam retornos ótimos e então os brasileiros em maioria não se sentiam estimulados a buscar retornos mais altos. Entretanto, diante das circunstâncias de contínuas reduções da Taxa Selic, considerando a inflação acumulada no ano de 2020, na prática, o rendimento real do investimento, se estivesse atrelado a Taxa Selic seria negativo. Isso porque o acumulado da inflação de 2020 indica que apesar do rendimento com a Taxa Selic, a perda do poder de compra resultante da inflação vai ultrapassar o rendimento.

Com essa perspectiva, o investidor deve se atentar às políticas monetárias, visto que isso pode redirecionar o resultado de seus investimentos. Dessa forma, a redução da taxa Selic foi fator de motivação para o movimento de migração de investidores para o mercado de capitais em 2020.

\subsubsection{O mercado de renda variável}

Em relação ao mercado de renda variável, segundo Lovato (2011), o fator principal que o difere da renda fixa é sua volatilidade. Dessa forma, o valor investido pode passar por oscilações ao longo do tempo, sem que haja garantia de rentabilidade futura.

Dentro do mercado de renda variável, há diversos ativos como é o caso das ações, fundos imobiliários, BDR's, isto é, Brazilian Depositary Receipts, e os ETF's, Exchange Traded Funds.

As ações podem ser negociadas, segundo Lovato (2011) tanto no mercado primário, isto é, quando determinada empresa faz sua abertura de capital, quanto no mercado secundário, mercado em que as negociações são feitas entre os investidores, depois da abertura ao mercado. Existem diversas estratégias para avaliar o valor de uma empresa, no momento de comprar ações, sendo as principais: análise gráfica - através do estudo do comportamento das ações ao longo do tempo - e análise fundamentalista, que avalia seus indicadores tais como rentabilidade, liquidez, endividamento e expectativa de crescimento, de acordo com Lovato (2011). 
Assim, de acordo com os pontos expostos, pode-se dizer que o mercado de renda variável teve grande popularização em 2020 devido a atratividade de sua performance ao longo dos anos e que vinha sendo percebida pelos investidores. Contudo, através deste aumento, houve também o crescimento do número de investidores no mercado de renda variável sem experiência suficiente que os tornem capazes de selecionar os melhores ativos alinhados com seus objetivos. Assim, o mercado de capitais se torna mais atrativo na perspectiva dos investidores devido a seus retornos, mas os novos investidores de perfil agressivo presentes no mercado de capitais passam a notar dificuldade no momento de iniciar seus investimentos de forma diversificada e eficaz.

\subsubsection{Exchange Traded Funds}

De acordo com Silva (2017), os Exchange Traded Funds (ETFs), são os fundos de investimentos em índices e possuem cotas negociadas em Bolsa de Valores. A proposta dos ETFs é replicar o comportamento de um índice de mercado.

Segundo Silva (2017), a Resolução CVM n³ 359/2002 define ETF como "comunhão de recursos destinado à aplicação em carteira de ativos financeiros que vise refletir as variações e rentabilidade de um índice de referência, por prazo indeterminado". Portanto, através dos fundos de índices, os investidores conseguem se expor a um ativo que replica determinado índice, guiado por critérios específicos que compõem cada ETF.

Cada um dos Exchange Traded Funds segue um índice que é guiado por direcionamentos diferentes. Pode-se exemplificar com base no SMAL11, fundo de índice que replica o índice das Small Caps que, segundo Silva (2017), são empresas de menor capitalização da BM\&FBovespa.

\subsubsection{Relação Risco x Retorno}

Conforme foi abordado anteriormente sobre a Teoria de portfólio, também conhecida como Teoria da carteira de Markowitz, a principal questão a ser tratada diz respeito ao problema de seleção de ativos que farão a composição do portfólio, segundo Lyrio (2014). 
Isso se dá devido a um problema de otimização, buscando o melhor equilíbrio entre risco e retorno.

\subsubsection{Rentabilidade}

Segundo Melo (2018), rentabilidade pode ser definida como o retorno resultante de algum investimento. Dentro deste conceito é possível identificar rentabilidade absoluta, definida em números absolutos e a rentabilidade relativa, ou seja, o retorno se baseia em algum parâmetro de comparação, fazendo uso de determinado benchmark, como CDI ou Ibovespa, por exemplo. De acordo com Melo (2018), percebemos também que a rentabilidade observada se refere ao retorno que determinado investimento já proporcionou no passado, diferente da rentabilidade esperada, e este não é garantido no futuro.

\subsubsection{Risco}

De acordo com Melo (2018), o risco é definido pela chance de que determinados eventos ocorram de forma diferente do esperado, podendo ser um cenário favorável ou não ao investidor, proporcionando assim, um cenário de incerteza.

Segundo Melo (2018), há três frentes de risco neste contexto: o risco de liquidez, vinculado a facilidade ou dificuldade de transformar um ativo em dinheiro pelo seu preço justo no momento desejado; o risco de crédito, quando o devedor não honra seus compromissos, sua dívida; e por fim o risco de mercado está relacionado com a variação dos preços de um ativo. No trabalho em questão, este é o risco que será considerado, visto que é o principal risco atrelado ao mercado de renda variável. O risco de mercado pode ser calculado de forma prática, através do desvio-padrão, que indica quanto os retornos de determinado ativo variam em comparação com a sua média, indicando sua volatilidade e, consequentemente, seu risco.

\subsubsection{3. Índice de Sharpe}


Segundo Varga (2001), o Índice de Sharpe se baseia na teoria de seleção de carteira, é uma fórmula usada como medida de desempenho ao comparar o retorno de determinado ativo, com o ativo livre de risco e a volatilidade deste ativo. A ideia é proporcionar de forma quantitativa a relação risco-retorno para que haja a possibilidade de comparação de diferentes ativos. Com isso, é possível fazer uma análise e relacionar investimentos diferentes considerando quanto de retorno cada um potencialmente oferece com base para um mesmo parâmetro de risco.

Assim, com base no cálculo em questão, é viável efetuar uma avaliação entre dois ou mais ativos com grande correlação, qual deles possui melhor relação risco-retorno.

\section{Metodologia}

O capítulo em questão tem como objetivo abordar a metodologia usada para realização da pesquisa, isto é, indicará a elaboração e fluxo do estudo, quais dados serão coletados e de que forma serão analisados. A estrutura do capítulo será dividida em algumas etapas, indicando o tipo de pesquisa, a amostra e coleta de dados, as variáveis e tratamento dos dados, a descrição do modelo a ser aplicado e limitações da metodologia.

\subsection{Tipo de pesquisa}

O presente trabalho visa identificar o comportamento dos principais Exchange Traded Funds presentes na bolsa brasileira e a relação risco e retorno, fazendo um comparativo entre dados históricos de rentabilidade e volatilidade através do índice de Sharpe dos ativos. O objetivo do estudo se dá pela identificação dos fundos de índices como uma oportunidade para investidores inexperientes que buscam investir em renda 
variável em carteiras já diversificadas e com custo menor.

Assim, a metodologia de pesquisa foi de natureza exploratória e quantitativa. Segundo Malhotra (2001), a pesquisa quantitativa tem como objetivo quantificar dados para generalização dos resultados da amostra para a população alvo. Em relação a pesquisa exploratória, de acordo com Gil (2002), esta permite maior familiaridade com o objeto de análise.

\subsection{Amostra e coleta de dados}

A amostra é composta pelas variáveis fundamentais de análise do ativo, que são o retorno médio mensal, a volatilidade e, consequentemente, índice de Sharpe dos principais ETFs disponíveis na bolsa brasileira para melhor análise da relação risco $\mathrm{x}$ retorno. São eles: Ishares Ibovespa (BOVA11), Ishares IBRX Brasil (BRAX11), It Now IDIV (DIVO11), Ishares Carbono Eficiente (ICO2) Brasil (ECO011), It Now IFNC (FIND11), It Now IGCT (GOVE11), It Now ISE (ISUS11), It Now PIBB IBRX-50 (PIBB11), Ishares BM\&FBOVESPA Small Cap (SMAL11).

Os dados históricos foram coletados através do site Investing.com, referência de preço de fechamento em tempo real no mercado financeiro. Com isso, foram retiradas as cotações dos ativos entre os anos de 2013 e 2021, assim proporcionando uma visão sólida dos ativos estudados, permitindo cálculo de retorno mensal, risco e variância, como apresentado no Anexo I e uma análise mais consistente em relação ao risco x retorno.

Dessa forma, a análise dos Exchange Traded Funds como "carteiras" diversificadas se deu em quatro etapas. Em primeiro lugar, foi feita a coleta dos dados acerca dos fundos de índices selecionados e, uma vez que os dados abrangem um contexto de oito anos, estes passam por diferentes cenários de mercado. Em segundo lugar, foram calculadas variáveis de análise com base nos dados históricos, estas sendo rentabilidade, risco e índice de Sharpe. Em terceiro lugar, foi selecionado o principal ETF listado na bolsa brasileira, o BOVA11, que replica o Ibovespa e foi indicado no Anexo II a composição mais recente da carteira teórica do benchmark. Em quarto lugar, foi analisado também os dados de rentabilidade, risco e índice de Sharpe de ativos que compõem o 
índice.

A rentabilidade mensal é, segundo Moura (2017), calculada pela média de todas as rentabilidades mensais de cada ativo. De acordo com Stringhini (2017), o desvio padrão e a variância são medidas de dispersão usadas para avaliar o risco dos investimentos, visto que esses indicam maior ou menor grau de variabilidade dos dados.

Dessa forma, para cálculo de rentabilidade será usada a seguinte fórmula:

$$
\text { Rentabilidade média }=\left(\frac{\text { Preço atual }}{\text { Preço anterior }} \times 100\right)-100
$$

Diante da pesquisa, para cálculo do Índice de Sharpe será usada segundo Varga (2001), a fórmula definida por:

\section{Índice de Sharpe $=$ Retorno do ativo - Taxa de retorno sem risco \\ Volatilidade do ativo}

Conforme indica Fonseca (2007), para cálculo do índice de Sharpe, considera-se como taxa livre de risco o CDI - certificado de depósito interbancário. Dessa forma, será possível fazer relação e análise entre as métricas selecionadas de ativos presentes na carteira teórica do lbovespa e o BOVA11, ETF que segue o benchmark. Em relação aos cálculos feitos, o resultado é apenas o resultado bruto, não levando em consideração possíveis custos de transação como taxas e tributos.

\subsubsection{Limitações do método}


Os estudos quantitativos, da mesma forma que outros tipos de pesquisa, apresentam limitações. Segundo Oliveira (2013), existe limitação da estatística, que em relação a compreensão de fenômenos complexos, estes que não são compreendidos por meio de dados matemáticos. O método, apesar de proporcionar base sólida de análise, não garante que os investimentos descritos terão grande aderência para o público em questão. Além disso, os valores coletados e aplicados ao índice de comparação, são baseados em dados históricos, sem garantia de realização futura.

É necessário destacar também que, segundo Brito (2001), para que haja uma comparação clara e aprofundada dos ativos usando, seria necessário correlação significativa entre eles, enquanto o Índice de Sharpe não considera tal correlação.

Apesar das limitações destacadas, a metodologia tem sucesso em explicitar com base em dados passados reais a oportunidade atrelada a classe de ativos dos Exchange Traded Funds, apesar de não garantir oportunidades futuras.

\section{Análise dos resultados}

Este capítulo apresenta as principais premissas e os resultados alcançados, analisa e discute as implicações, sobre a relação risco e retorno, através do índice de Sharpe do BOVA11 e de ativos que compõem o lbovespa isoladamente.

Através da busca pelos dados presentes no Anexo I, foi possível a coleta de dados históricos dos principais ETFs da bolsa brasileira desde 2013 até 2021 e, consequentemente, o cálculo da rentabilidade de rentabilidade, risco e índice de Sharpe dos principais ETFs listados na bolsa brasileira.

Com a intenção de gerar maior compreensão sobre os dados, foi feito o cálculo de diferentes fundos de índice para que seja possível uma base racional mais completa, com visão macro do contexto dos Exchange Traded Funds, expostos na Tabela 3.

\section{Tabela 3: Relação risco x retorno dos principais ETFs brasileiros.}




\begin{tabular}{|l|r|r|r|r|r|r|r|r|r|}
\hline & BOVA11 & BRAX11 & DIVO11 & ECO011 & FIND11 & GOVE11 & ISUS11 & PIBB11 & SMAL11 \\
\hline Retorno médio & $0,94 \%$ & $1,11 \%$ & $0,96 \%$ & $0,95 \%$ & $1,44 \%$ & $1,17 \%$ & $0,72 \%$ & $1,10 \%$ & $0,95 \%$ \\
\hline Risco (desvio padrão) & $6,77 \%$ & $6,45 \%$ & $7,15 \%$ & $6,67 \%$ & $8,22 \%$ & $6,44 \%$ & $5,77 \%$ & $6,67 \%$ & $7,10 \%$ \\
\hline Indice Sharpe & $\mathbf{0 , 0 3 8 7}$ & $\mathbf{0 , 0 6 6 5}$ & $\mathbf{0 , 0 3 8 6}$ & $\mathbf{0 , 0 4 0 8}$ & $\mathbf{0 , 0 9 2 5}$ & $\mathbf{0 , 0 7 5 6}$ & $\mathbf{0 , 0 0 6 4}$ & $\mathbf{0 , 0 6 3 0}$ & $\mathbf{0 , 0 3 7 9}$ \\
\hline
\end{tabular}

Fonte: Desenvolvido pela aluna.

Para fins de comparação de forma quantitativa e assim possibilitar análise de forma mais aprofundada, o Anexo II corresponde a versão atualizada de junho de 2021 da carteira teórica do lbovespa, índice referencial para grande parte dos investimentos em renda variável, além das respectivas participações das ações isoladamente dentro do índice.

Assim, foram selecionadas três ações para serem calculadas isoladamente e então comparadas com o índice, para fins de análise da carteira. As duas primeiras: VALE3 e ITUB4 são os ativos com maior participação na carteira teórica atualizada. Já a terceira ação é a COGN3, essa se refere a uma ação de pequena participação na carteira teórica, a fim de analisar os resultados encontrados e verificar o peso dos resultados sobre o índice total.

Primeiramente, de modo a indicar os pontos principais da carteira teórica, a Tabela 4 indica a proporção de cada um dos ativos selecionados dentro do lbovespa, para que a análise possa se basear na proporção de cada um desses na construção do índice.

Tabela 4: Peso dos ativos dentro do Ibovespa

\begin{tabular}{|c|c|c|}
\hline Código do Ativo & Ação & Participação (\%) \\
\hline VALE3 & VALE & $11,71 \%$ \\
\hline ITUB4 & ITAÚ UNIBANCO & $6,74 \%$ \\
\hline COGN3 & COGNA & $0,35 \%$ \\
\hline
\end{tabular}

Fonte: desenvolvido pela aluna. 
Com isso, considerando a carteira teórica do lbovespa mais atualizada, através das duas ações com maior participação - VALE3 e ITUB4 - é possível análise de ações expressivas no índice, enquanto uma das menores participações - COGN3 - foi uma escolha randômica dentre os ativos mais inexpressivos percentualmente, para visualização dessa relação.

Dessa forma, ao considerar os ativos selecionados de forma isolada, foram usadas as fórmulas mostradas anteriormente para cálculo do índice de Sharpe, retorno médio e risco. Como o Anexo III apresenta, foi feito o cálculo das mesmas métricas das ações isoladamente, visando uma análise mais robusta da relação dos ativos. A Tabela 4 explicita os resultados obtidos das ações e também do ETF.

Tabela 4: Relação risco x retorno das ações de VALE3, ITUB4 COGN3 e do BOVA11

\begin{tabular}{|l|r|r|r|r|}
\hline & \multicolumn{1}{|c|}{ VALE3 } & \multicolumn{1}{|c|}{ ITUB4 } & \multicolumn{1}{c|}{ COGN3 } & \multicolumn{1}{c|}{ BOVA11 } \\
\hline Retorno médio & $1,91 \%$ & $1,43 \%$ & $0,95 \%$ & $0,94 \%$ \\
\hline Risco (desvio padrão) & $11,23 \%$ & $8,54 \%$ & $13,91 \%$ & $6,77 \%$ \\
\hline Indice Sharpe & $\mathbf{0 , 1 0 9 7}$ & $\mathbf{0 , 0 8 8 2}$ & $\mathbf{0 , 0 1 9 2}$ & $\mathbf{0 , 0 3 8 7}$ \\
\hline
\end{tabular}

\section{Fonte: Desenvolvido pela aluna.}

Diante dos dados expostos, é possível verificar que mesmo com a volatilidade das três ações isoladamente maior do que o risco do BOVA11, suas respectivas rentabilidades superaram o fundo de índice. Enquanto o retorno médio do BOVA11 foi de 0,94\%, o retorno dos outros três ativos foi maior, sendo o maior deles o da VALE3, com 1,91\%.

Com isso, para que seja analisada a relação entre o risco e o retorno de cada um dos investimentos, é necessário mirar no índice de Sharpe, visto que este já considera as duas variáveis. Sendo assim, com 0,1097 e 0,0882 respectivamente, tanto VALE3 quanto ITUB4 possuem índice de Sharpe superior ao BOVA11, que possui 0,0387. Isso porque, apesar da volatilidade de ambos ser superior a do ETF, o retorno compensa e proporciona melhor relação.

Em contrapartida, ao analisar COGN3 é possível verificar uma rentabilidade próxima ao retorno do BOVA11 mas com grande diferença na volatilidade, sendo que a primeira 
possui aproximadamente o dobro do risco. Assim, o índice de Sharpe de BOVA11 é superior ao de COGN3.

\section{Conclusão}

O estudo teve a pretensão de investigar mais a fundo sobre uma classe de ativos, os fundos de índice, de modo a identificá-los como carteiras diversificadas e com baixa taxa de administração, sendo assim um potencial produto diferenciado para investidores entrantes no mercado de capitais. A ideia se baseou na possibilidade de analisar uma redução do risco ao alocar diretamente em ativos diversificados se comparado aos ativos isoladamente.

$\mathrm{Na}$ busca pelo resultado, foram coletados dados históricos dos principais ETFs presentes no mercado de capitais brasileiro, do CDI - sendo considerado referência para taxa livre de risco - necessário para cálculo do índice de Sharpe e também os dados históricos das cotações das ações escolhidas.

Para chegar ao valor, foi calculado o retorno médio, a volatilidade e o índice de Sharpe do principal índice da bolsa brasileira, o BOVA11 e também de três ações selecionadas que pertencem a carteira teórica do lbovespa visando alcançar dados quantitativos que analisassem a eficácia da alocação nos ETFs.

Diante dos resultados obtidos, ficou evidente que dentro da carteira teórica do Ibovespa há diversas ações, com diferentes retornos e volatilidades e cada uma possui um impacto percentualmente sobre o índice. Entretanto, considerando a carteira teórica de junho de 2021, as ações de maior participação no índice, apesar da significativa volatilidade, tiveram um retorno significativo e que resultou em índice de Sharpe superior ao do BOVA11. Isso significa que se o investidor investisse diretamente em VALE3 ou ITUB4 isoladamente, sua relação risco $\mathrm{x}$ retorno estaria mais eficiente do que se colocasse no BOVA11, visto que para um mesmo nível de risco, as duas ações proporcionariam maior rentabilidade no período estudado do que o BOVA11. 
Entretanto, investidores entrantes que estão interessados em investir na bolsa isoladamente correm risco alto. Isso porque o investidor pessoa física no Brasil, por ser um público muito novo, ainda carece de educação financeira, não conhece os ativos com profundidade e, com isso, podem alocar em algum dos ativos da carteira teórica com menor índice de Sharpe, se comparado ao BOVA11 como carteira diversificada.

Dessa forma, o investidor inexperiente, por inexperiência ou falta de conhecimento não sabe identificar o ativo com maior índice de Sharpe dentro na carteira teórica, portanto mesmo com o índice menos atrativo no ETF, o investidor não corre o risco de alocar em ações de maior volatilidade. Isso significa que ele poderia escolher por exemplo a VALE3, que possui boa relação, mas poderia também por inexperiência escolher COGN3, que já seria mais arriscado. Por isso, apesar do ETF não ser a alocação mais eficiente, ele proporciona algo que investimentos isolados não proporcionam, diversificação e, consequentemente, redução do risco específico.

\section{Referências Bibliográficas}

BCB - Taxas de juros básicas - Histórico

<https://www.bcb.gov.br/controleinflacao/historicotaxasjuros>

BERTÃO, N. Investidores pessoa física são mais de 3 milhões na B3 pela primeira vez. $<$ https://valorinveste.globo.com/mercados/renda-variavel/noticia/2020/10/02/investidorespessoa-fisica-sao-mais-de-3-milhoes-na-b3-pela-1a-vez.ghtml >

BONA, A. 11 motivos para começar a investir seu dinheiro hoje mesmo.

<https://andrebona.com.br/11-motivos-para-comecar-a-investir-seu-dinheiro-hoje-mesmo/ >

BORGES, E. Exchange Traded Funds versus Fundos Indexados no Brasil. <https://gvpesquisa.fgv.br/sites/gvpesquisa.fgv.br/files/arquivos/eid - 
exchange 
traded funds versus fundos indexados no brasil.pdf>

BRITO, N. A relevância geral do Índice de Sharpe

$<$ <ttp://repositorio.ipea.gov.br/handle/11058/5113>

CARDOZO, T. Análise do Perfil de Investidores Brasileiros.

<http://aprepro.org.br/conbrepro/2019/anais/arquivos/09292019140900 5d90e7fc62875.pd f>

CONGO, M. O que é investimento? Entenda tudo sobre o conceito de investimento financeiro. <https://blog.magnetis.com.br/o-que-e-

investimento/\#: :text=Investimento\%20\%C3\%A9\%20qualquer\%20gasto\%20ou,capital\%20i ntelectual\%2C\%20social\%20ou\%20natural>

D’ÁVILA, M. Bolsa se aproxima de 1 milhão de investidorees, mas ainda é pouco.

$<$ https://www.infomoney.com.br/onde-investir/bolsa-se-aproxima-de-1-milhao-de-

investidores-mas-ainda-e-pouco/>

FAYH, M. Como fazer a alocação de ativos ideal para seu dinheiro render mais.

<https://comoinvestir.thecap.com.br/alocacao-de-ativos/\#Protecao (Moedas e Ouro)>

FOGAÇA, A. Tripé dos Investimentos: Como escolher o melhor investimento.

$<$ https://comoinvestir.thecap.com.br/tripe-dos-investimentos/>

GOLDFAJN, I. Política Monetária no Brasil.

<https://www.bcb.gov.br/htms/relinf/port/2002/12/ri200212b5p.pdf >

JÚNIOR, J. Visão geral da conjuntura.

<https://www.ipea.gov.br/cartadeconjuntura/index.php/tag/previsoes-macroeconomicas/>

LAPORTA, T. Bolsa brasileira alcança a marca de 3 milhões de investidores pessoas

físicas. <https://investnews.com.br/financas/bolsa-brasileira-alcanca-a-marca-de-3-milhoesde-investidores-pessoas-fisicas/>

LEMOS, A. Política monetária: tudo sobre essa ferramenta econômica. 
$<$ https://empreenderdinheiro.com.br/blog/politica-

monetaria/\#: :text=Para\%20exercer\%20uma\%20pol\%C3\%ADtica\%20monet\%C3\%A1ria,qu e\%20\%C3\%A9\%20definida\%20pelo\%20Copom. $>$

LOVATO, B. Finanças pessoais: investimentos de renda fixa e renda variável. $<$ http://tcc.bu.ufsc.br/Contabeis295850>

MATSUMOTO A. Gestão de carteiras: os benefícios da diversificação mundial no mercado acionário.

<https://www.fundace.org.br/revistaracef/index.php/racef/article/view/160/pdf $21>$

MELO, I. Investimentos em renda fixa e renda variável.

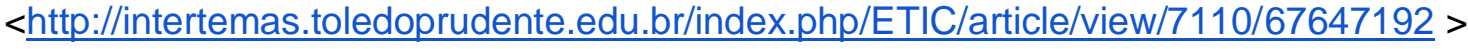

MIOZZO, J. O que é a Taxa Selic e como ela afeta seu dinheiro?

<https://blog.nubank.com.br/taxa-selic/ >

PINTO, L. Segurança, rentabilidade e liquidez: entenda o conceito de Tripé dos Investimentos.

$<$ https://conteudos.xpi.com.br/aprenda-a-investir/relatorios/seguranca-rentabilidade-eliquidez-entenda-o-conceito-de-tripe-dos-investimentos/ >

RAMBO, A. O perfil do investidor e melhores investimentos: da teoria à prática do mercado brasileiro.

$<$ https://repositorio.ufsc.br/xmlui/bitstream/handle/123456789/123812/Monografia\%20da\%2 0Andrea\%20Rambo.pdf? sequence $=1$ \&isAllowed $=\mathrm{y}>$

SALVALÁGIO, A. Análise e evolução da taxa Selic meta em relação à taxa Selic efetiva e seus reflexos sobre a dívida pública interna.

<http://tcc.bu.ufsc.br/Economia295499.pdf>

SILVA, A. Um estudo da performance do ETF Ishares Small cap em relação ao índice Bovespa. <https://repositorio.ufmg.br/bitstream/1843/35061/1/Andressa\%20Cardoso\%20\%20Vers\%C3\%A30\%20Final.pdf> 
SILVEIRA, D. Desemprego diante da pandemia bate recorde no Brasil em setembro, aponta IBGE.

<https://g1.globo.com/economia/noticia/2020/10/23/no-de-desempregados-diante-da-

pandemia-aumentou-em-34-milhoes-em-cinco-meses-aponta-ibge.ghtml>

Varga, G. Índice de Sharpe e outros indicadores de performance aplicados a fundos de ações brasileiros.

<https://www.scielo.br/j/rac/a/VcTL5k9VvhyL7FkTfQfPX6Q/?lang=pt\&format=pdf >

\section{Anexo}

Anexo I

\begin{tabular}{|c|l|l|l|l|l|l|l|l|l|l|}
\hline Pricing Date & CDI & $\begin{array}{c}\text { BOVA11 } \\
- \text { Índice } \\
\text { Bovespa }\end{array}$ & $\begin{array}{c}\text { BRAX11 - } \\
\text { IBRX }\end{array}$ & DIVO11 & $\begin{array}{c}\text { ECOO11 } \\
- \text { ICO2 }\end{array}$ & $\begin{array}{c}\text { FIND11 } \\
\text { - IFNC }\end{array}$ & $\begin{array}{c}\text { GOVE11 } \\
- \text { IGTC }\end{array}$ & $\begin{array}{c}\text { ISUS11 } \\
- \text { ISE - }\end{array}$ & $\begin{array}{c}\text { PIBB11 } \\
\text { IBX50 }\end{array}$ & $\begin{array}{c}\text { SML1 } \\
\text { SMLL }\end{array}$ \\
\hline dez.-12 & & & & & & & & & & \\
\hline jan.-13 & $0,59 \%$ & $-1,68 \%$ & $0,16 \%$ & $-2,32 \%$ & $1,42 \%$ & $0,74 \%$ & $0,37 \%$ & $-0,42 \%$ & $-0,61 \%$ & $0,28 \%$ \\
\hline fev.-13 & $0,48 \%$ & $-4,34 \%$ & $-2,91 \%$ & $-0,38 \%$ & $-2,08 \%$ & $1,44 \%$ & $-0,88 \%$ & $0,29 \%$ & $-3,87 \%$ & $0,18 \%$ \\
\hline mar.-13 & $0,54 \%$ & $-1,85 \%$ & $0,61 \%$ & $-1,34 \%$ & $-0,20 \%$ & $3,85 \%$ & $-0,37 \%$ & $0,21 \%$ & $0,91 \%$ & $-3,94 \%$ \\
\hline abr.-13 & $0,60 \%$ & $-1,18 \%$ & $0,19 \%$ & $0,24 \%$ & $-1,79 \%$ & $-2,37 \%$ & $-0,94 \%$ & $0,42 \%$ & $0,41 \%$ & $-0,21 \%$ \\
\hline mai.-13 & $0,58 \%$ & $-3,67 \%$ & $-0,35 \%$ & $-2,44 \%$ & $-1,00 \%$ & $5,51 \%$ & $-1,46 \%$ & $-2,07 \%$ & $0,34 \%$ & $-1,91 \%$ \\
\hline
\end{tabular}




\begin{tabular}{|c|c|c|c|c|c|c|c|c|c|c|}
\hline jun.-13 & $0,59 \%$ & $\mid-11,34 \%$ & $\mid-8,91 \%$ & $\mid-7,34 \%$ & $-6,43 \%$ & $-12,95 \%$ & $-7,77 \%$ & $-6,39 \%$ & $-9,88 \%$ & $-9,86 \%$ \\
\hline jul.-13 & $0,71 \%$ & $1,76 \%$ & $1,57 \%$ & $2,27 \%$ & $0,80 \%$ & $1,25 \%$ & $3,43 \%$ & $2,62 \%$ & $1,06 \%$ & $0,02 \%$ \\
\hline ago.-13 & $0,70 \%$ & $4,61 \%$ & $0,81 \%$ & $1,27 \%$ & $1,17 \%$ & $-0,76 \%$ & $0,10 \%$ & $2,42 \%$ & $3,09 \%$ & $-1,21 \%$ \\
\hline set.-13 & $0,70 \%$ & $3,62 \%$ & $6,00 \%$ & $6,24 \%$ & $5,75 \%$ & $9,82 \%$ & $4,77 \%$ & $3,74 \%$ & $5,15 \%$ & $4,88 \%$ \\
\hline out.-13 & $0,80 \%$ & $2,75 \%$ & $5,33 \%$ & $5,84 \%$ & $3,73 \%$ & $6,16 \%$ & $4,89 \%$ & $4,89 \%$ & $6,21 \%$ & $-0,99 \%$ \\
\hline nov.-13 & $0,71 \%$ & $-2,69 \%$ & $-2,08 \%$ & $-3,82 \%$ & $-2,77 \%$ & $-4,10 \%$ & $-2,47 \%$ & $-1,98 \%$ & $-2,54 \%$ & $-0,97 \%$ \\
\hline dez.-13 & $0,78 \%$ & $-2,03 \%$ & $-3,11 \%$ & $-1,80 \%$ & $-2,58 \%$ & $-4,70 \%$ & $-1,87 \%$ & $-1,37 \%$ & $-3,40 \%$ & $-1,75 \%$ \\
\hline jan.-14 & $0,84 \%$ & $-7,52 \%$ & $-8,04 \%$ & $-7,26 \%$ & $-7,22 \%$ & $-8,82 \%$ & $-7,59 \%$ & $-6,87 \%$ & $-8,19 \%$ & $-8,34 \%$ \\
\hline fev.-14 & $0,78 \%$ & $-0,82 \%$ & $-0,44 \%$ & $-2,10 \%$ & $2,02 \%$ & $5,05 \%$ & $0,36 \%$ & $-2,06 \%$ & $-0,25 \%$ & $-1,19 \%$ \\
\hline mar.-14 & $0,76 \%$ & $6,53 \%$ & $6,89 \%$ & $7,12 \%$ & $6,26 \%$ & $11,23 \%$ & $6,18 \%$ & $5,73 \%$ & $6,92 \%$ & $4,28 \%$ \\
\hline abr.-14 & $0,82 \%$ & $2,44 \%$ & $2,68 \%$ & $2,25 \%$ & $3,13 \%$ & $6,64 \%$ & $2,52 \%$ & $2,33 \%$ & $3,06 \%$ & $-0,84 \%$ \\
\hline mai.-14 & $0,86 \%$ & $-0,62 \%$ & $1,02 \%$ & $-2,82 \%$ & $-2,32 \%$ & $-1,69 \%$ & $-1,23 \%$ & $-1,70 \%$ & $-1,37 \%$ & $0,98 \%$ \\
\hline jun.-14 & $0,82 \%$ & $3,42 \%$ & $1,41 \%$ & $4,52 \%$ & $2,85 \%$ & $5,02 \%$ & $3,93 \%$ & $4,42 \%$ & $3,57 \%$ & $2,49 \%$ \\
\hline jul.-14 & $0,94 \%$ & $5,11 \%$ & $4,46 \%$ & $5,93 \%$ & $4,41 \%$ & $4,90 \%$ & $3,73 \%$ & $2,38 \%$ & $5,26 \%$ & $-3,25 \%$ \\
\hline ago.-14 & $0,86 \%$ & $9,87 \%$ & $9,54 \%$ & $7,78 \%$ & $9,84 \%$ & $13,11 \%$ & $8,39 \%$ & $5,04 \%$ & $9,93 \%$ & $7,36 \%$ \\
\hline set.-14 & $0,90 \%$ & $-11,81 \%$ & $-11,21 \%$ & $-12,85$ & $-9,61 \%$ & $-13,0$ & $-10,32 \%$ & $-6,75 \%$ & $-11,53 \%$ & $-9,33 \%$ \\
\hline out.-14 & $0,94 \%$ & $0,65 \%$ & $0,84 \%$ & $-5,55 \%$ & $0,03 \%$ & $1,89 \%$ & $3,02 \%$ & $1,25 \%$ & $1,11 \%$ & $-1,60 \%$ \\
\hline nov.-14 & $0,84 \%$ & $0,32 \%$ & $0,59 \%$ & $-2,61 \%$ & $7,03 \%$ & $6,22 \%$ & $1,95 \%$ & $1,63 \%$ & $0,16 \%$ & $-0,64 \%$ \\
\hline dez.-14 & $0,96 \%$ & $-8,67 \%$ & $-8,39 \%$ & $-10,82 \%$ & $-7,48 \%$ & $-8,29 \%$ & $-7,26 \%$ & $-6,10 \%$ & $-8,59 \%$ & $-7,28 \%$ \\
\hline jan.-15 & $0,93 \%$ & $-6,04 \%$ & $-5,83 \%$ & $-11,06 \%$ & $-3,01 \%$ & $-5,49 \%$ & $-6,57 \%$ & $-5,75 \%$ & $-5,39 \%$ & $-11,90 \%$ \\
\hline fev.-15 & $0,82 \%$ & $9,65 \%$ & $9,26 \%$ & $10,14 \%$ & $9,99 \%$ & $12,11 \%$ & $8,89 \%$ & $8,57 \%$ & $9,76 \%$ & $5,77 \%$ \\
\hline mar.-15 & $1,04 \%$ & $-1,02 \%$ & $-0,50 \%$ & $-4,02 \%$ & $-1,02 \%$ & $-1,51 \%$ & $-0,60 \%$ & $-2,16 \%$ & $-0,79 \%$ & $0,87 \%$ \\
\hline abr.-15 & $0,95 \%$ & $10,34 \%$ & $9,07 \%$ & $12,00 \%$ & $6,49 \%$ & $8,30 \%$ & $7,05 \%$ & $7,03 \%$ & $9,72 \%$ & $2,88 \%$ \\
\hline mai.-15 & $0,98 \%$ & $-5,99 \%$ & $-5,40 \%$ & $-6,77 \%$ & $-5,51 \%$ & $-8,00 \%$ & $-5,37 \%$ & $-4,35 \%$ & $-6,01 \%$ & $-2,16 \%$ \\
\hline jun.-15 & $1,07 \%$ & $0,21 \%$ & $0,60 \%$ & $-2,59 \%$ & $-0,05 \%$ & $3,55 \%$ & $0,00 \%$ & $-0,28 \%$ & $0,66 \%$ & $-1,35 \%$ \\
\hline jul.-15 & $1,18 \%$ & $-4,06 \%$ & $-3,36 \%$ & $-3,44 \%$ & $-1,35 \%$ & $-4,14 \%$ & $-2,75 \%$ & $-0,61 \%$ & $-3,75 \%$ & $-3,75 \%$ \\
\hline ago.-15 & $1,11 \%$ & $-8,16 \%$ & $-8,01 \%$ & $-10,82 \%$ & $-7,47 \%$ & $-10,42 \%$ & $-8,85 \%$ & $-6,35 \%$ & $-7,85 \%$ & $-8,87 \%$ \\
\hline set.-15 & $1,11 \%$ & $-4,21 \%$ & $-3,29 \%$ & $-6,17 \%$ & $-1,87 \%$ & $-4,46 \%$ & $-1,96 \%$ & $-3,50 \%$ & $-3,33 \%$ & $-2,99 \%$ \\
\hline out.-15 & $1,11 \%$ & $2,23 \%$ & $1,37 \%$ & $6,44 \%$ & $-0,86 \%$ & $1,48 \%$ & $1,00 \%$ & $0,77 \%$ & $1,08 \%$ & $5,48 \%$ \\
\hline nov.-15 & $1,06 \%$ & $-1,58 \%$ & $-1,40 \%$ & $-7,01 \%$ & $-0,70 \%$ & $3,19 \%$ & $-1,67 \%$ & $-3,20 \%$ & $-1,79 \%$ & $-2,07 \%$ \\
\hline dez.-15 & $1,16 \%$ & $-3,59 \%$ & $-3,94 \%$ & $-4,03 \%$ & $-3,96 \%$ & $-4,55 \%$ & $-3,40 \%$ & $-2,37 \%$ & $-3,94 \%$ & $-4,68 \%$ \\
\hline jan.-16 & $1,05 \%$ & $-6,98 \%$ & $-6,23 \%$ & $-9,46 \%$ & $-7,47 \%$ & $-5,38 \%$ & $-6,37 \%$ & $-5,05 \%$ & $-6,41 \%$ & $-9,20 \%$ \\
\hline fev.-16 & $1,00 \%$ & $5,77 \%$ & $5,12 \%$ & $8,67 \%$ & $8,59 \%$ & $5,21 \%$ & $6,33 \%$ & $3,11 \%$ & $5,60 \%$ & $5,14 \%$ \\
\hline mar.-16 & $1,16 \%$ & $17,35 \%$ & $15,98 \%$ & $19,88 \%$ & $15,36 \%$ & $23,15 \%$ & $12,96 \%$ & $6,52 \%$ & $16,43 \%$ & $11,60 \%$ \\
\hline abr.-16 & $1,05 \%$ & $7,22 \%$ & $6,72 \%$ & $13,03 \%$ & $4,43 \%$ & $9,02 \%$ & $7,23 \%$ & $2,05 \%$ & $7,30 \%$ & $5,42 \%$ \\
\hline mai.-16 & $1,11 \%$ & $-9,84 \%$ & $-8,45 \%$ & $-11,45 \%$ & $-8,11 \%$ & $-12,19 \%$ & $-8,20 \%$ & $-5,15 \%$ & $-9,90 \%$ & $-5,12 \%$ \\
\hline jun.-16 & $1,16 \%$ & $6,13 \%$ & $5,45 \%$ & $6,61 \%$ & $3,98 \%$ & $7,50 \%$ & $5,51 \%$ & $3,16 \%$ & $6,01 \%$ & $9,47 \%$ \\
\hline jul.-16 & $1,11 \%$ & $11,58 \%$ & $10,95 \%$ & $12,79 \%$ & $10,95 \%$ & $10,16 \%$ & $11,19 \%$ & $12,71 \%$ & $11,01 \%$ & $14,55 \%$ \\
\hline ago.-16 & $1,21 \%$ & $0,45 \%$ & $1,39 \%$ & $2,23 \%$ & $0,30 \%$ & $1,84 \%$ & $0,85 \%$ & $0,61 \%$ & $1,08 \%$ & $0,00 \%$ \\
\hline set.-16 & $1,11 \%$ & $1,13 \%$ & $0,63 \%$ & $-0,50 \%$ & $0,94 \%$ & $-0,38 \%$ & $0,00 \%$ & $-0,12 \%$ & $0,85 \%$ & $0,14 \%$ \\
\hline out.-16 & $1,05 \%$ & $11,21 \%$ & $10,43 \%$ & $15,03 \%$ & $7,23 \%$ & $12,82 \%$ & $10,61 \%$ & $6,18 \%$ & $11,02 \%$ & $7,05 \%$ \\
\hline nov.-16 & $1,04 \%$ & $-4,61 \%$ & $-4,80 \%$ & $-2,35 \%$ & $-4,93 \%$ & $-7,08 \%$ & $-4,70 \%$ & $-7,45 \%$ & $-4,55 \%$ & $-7,56 \%$ \\
\hline dez.-16 & $1,04 \%$ & $-2,93 \%$ & $-2,59 \%$ & $-0,96 \%$ & $-2,51 \%$ & $-2,00 \%$ & $-1,79 \%$ & $-1,40 \%$ & $-2,70 \%$ & $-1,64 \%$ \\
\hline
\end{tabular}




\begin{tabular}{|c|c|c|c|c|c|c|c|c|c|c|}
\hline jan.-17 & $1,08 \%$ & $7,13 \%$ & $7,28 \%$ & $8,56 \%$ & $5,84 \%$ & $8,73 \%$ & $8,46 \%$ & $2,21 \%$ & $6,93 \%$ & |11,83\% \\
\hline fev.-17 & $0,86 \%$ & $3,38 \%$ & $3,22 \%$ & $6,88 \%$ & $3,75 \%$ & $6,30 \%$ & $3,73 \%$ & $2,85 \%$ & $2,92 \%$ & $5,45 \%$ \\
\hline mar.-17 & $1,05 \%$ & $-2,67 \%$ & $-2,49 \%$ & $-1,86 \%$ & $0,52 \%$ & $-1,51 \%$ & $-2,20 \%$ & $-0,44 \%$ & $-2,17 \%$ & $-1,61 \%$ \\
\hline abr.-17 & $0,79 \%$ & $0,65 \%$ & $1,04 \%$ & $1,01 \%$ & $1,22 \%$ & $0,26 \%$ & $1,44 \%$ & $1,83 \%$ & $0,70 \%$ & $3,39 \%$ \\
\hline mai.-17 & $0,93 \%$ & $-4,16 \%$ & $-3,69 \%$ & $-5,68 \%$ & $-4,34 \%$ & $-7,27 \%$ & $-3,63 \%$ & $-1,68 \%$ & $-3,91 \%$ & $-0,80 \%$ \\
\hline jun.-17 & $0,81 \%$ & $0,61 \%$ & $0,58 \%$ & $-1,34 \%$ & $0,39 \%$ & $2,08 \%$ & $0,90 \%$ & $-1,59 \%$ & $0,33 \%$ & $0,08 \%$ \\
\hline jul.-17 & $0,80 \%$ & $4,58 \%$ & $4,59 \%$ & $4,82 \%$ & $3,90 \%$ & $3,96 \%$ & $4,81 \%$ & $3,64 \%$ & $4,81 \%$ & $8,26 \%$ \\
\hline ago.-17 & $0,80 \%$ & $7,36 \%$ & $7,16 \%$ & $6,50 \%$ & $6,12 \%$ & $6,10 \%$ & $7,62 \%$ & $6,24 \%$ & $7,31 \%$ & $8,67 \%$ \\
\hline set.-17 & $0,64 \%$ & $4,63 \%$ & $4,71 \%$ & $6,63 \%$ & $5,86 \%$ & $6,99 \%$ & $4,53 \%$ & $5,06 \%$ & $5,02 \%$ & $3,43 \%$ \\
\hline out.-17 & $0,64 \%$ & $0,27 \%$ & $0,41 \%$ & $0,50 \%$ & $-0,43 \%$ & $-1,32 \%$ & $-0,51 \%$ & $0,00 \%$ & $0,11 \%$ & $-1,28 \%$ \\
\hline nov.-17 & $0,57 \%$ & $-3,30 \%$ & $-4,50 \%$ & $-6,81 \%$ & $-3,65 \%$ & $-4,28 \%$ & $-3,66 \%$ & $-7,09 \%$ & $-3,19 \%$ & $-2,80 \%$ \\
\hline dez.-17 & $0,54 \%$ & $6,37 \%$ & $6,96 \%$ & $5,22 \%$ & $3,20 \%$ & $4,55 \%$ & $3,60 \%$ & $6,35 \%$ & $6,28 \%$ & $7,60 \%$ \\
\hline jan.-18 & $0,58 \%$ & $11,08 \%$ & $11,00 \%$ & $10,52 \%$ & $13,86 \%$ & $20,19 \%$ & $13,29 \%$ & $7,81 \%$ & $11,53 \%$ & $4,01 \%$ \\
\hline fev.-18 & $0,46 \%$ & $0,61 \%$ & $1,00 \%$ & $0,44 \%$ & $-0,44 \%$ & $-0,07 \%$ & $-1,52 \%$ & $-2,89 \%$ & $0,36 \%$ & $-0,65 \%$ \\
\hline mar.-18 & $0,53 \%$ & $-0,08 \%$ & $-0,43 \%$ & $-0,87 \%$ & $-0,05 \%$ & $0,24 \%$ & $0,80 \%$ & $0,47 \%$ & $0,21 \%$ & $0,12 \%$ \\
\hline abr.-18 & $0,52 \%$ & $0,91 \%$ & $0,46 \%$ & $-1,21 \%$ & $-2,18 \%$ & $-3,94 \%$ & $0,74 \%$ & $0,67 \%$ & $0,58 \%$ & $2,17 \%$ \\
\hline mai.-18 & $0,52 \%$ & $-10,95 \%$ & $-11,12 \%$ & $-11,21 \%$ & $-12,74 \%$ & $-14,80 \%$ & $-10,41 \%$ & $-8,41 \%$ & $-10,82 \%$ & $-11,18 \%$ \\
\hline jun.-18 & $0,52 \%$ & $-5,02 \%$ & $-5,10 \%$ & $-3,86 \%$ & $-6,10 \%$ & $-6,54 \%$ & $-7,28 \%$ & $-1,57 \%$ & $-5,34 \%$ & $-3,68 \%$ \\
\hline jul.-18 & $0,54 \%$ & $8,67 \%$ & $9,19 \%$ & $7,11 \%$ & $9,03 \%$ & $12,72 \%$ & $11,34 \%$ & $3,30 \%$ & $9,04 \%$ & $5,19 \%$ \\
\hline ago.-18 & $0,57 \%$ & $-3,05 \%$ & $-3,04 \%$ & $-3,65 \%$ & $-4,16 \%$ & $-4,72 \%$ & $-3,28 \%$ & $-1,97 \%$ & $-2,94 \%$ & $-4,16 \%$ \\
\hline set.-18 & $0,47 \%$ & $3,36 \%$ & $3,07 \%$ & $0,45 \%$ & $1,66 \%$ & $1,51 \%$ & $3,49 \%$ & $-1,57 \%$ & $3,69 \%$ & $-1,76 \%$ \\
\hline out.-18 & $0,54 \%$ & $9,75 \%$ & $10,26 \%$ & $11,11 \%$ & $12,16 \%$ & $17,16 \%$ & $11,52 \%$ & $10,14 \%$ & $9,50 \%$ & $12,41 \%$ \\
\hline nov.-18 & $0,49 \%$ & $2,72 \%$ & $3,02 \%$ & $7,92 \%$ & $5,70 \%$ & $8,08 \%$ & $3,54 \%$ & $4,05 \%$ & $2,46 \%$ & $5,51 \%$ \\
\hline dez.-18 & $0,49 \%$ & $-2,05 \%$ & $-1,77 \%$ & $0,21 \%$ & $-5,30 \%$ & $-0,76 \%$ & $-4,08 \%$ & $0,36 \%$ & $-1,98 \%$ & $1,23 \%$ \\
\hline jan.-19 & $0,54 \%$ & $11,11 \%$ & $11,24 \%$ & $13,08 \%$ & $18,44 \%$ & $17,13 \%$ & $14,40 \%$ & $10,30 \%$ & $10,26 \%$ & $9,48 \%$ \\
\hline fev.-19 & $0,49 \%$ & $-2,29 \%$ & $-1,94 \%$ & $-2,29 \%$ & $-3,58 \%$ & $-2,52 \%$ & $-1,08 \%$ & $-2,78 \%$ & $-0,79 \%$ & $-2,03 \%$ \\
\hline mar.-19 & $0,47 \%$ & $-0,04 \%$ & $-0,13 \%$ & $-1,25 \%$ & $-5,25 \%$ & $-4,49 \%$ & $-1,82 \%$ & $-8,58 \%$ & $-1,10 \%$ & $0,34 \%$ \\
\hline abr.-19 & $0,52 \%$ & $1,17 \%$ & $1,02 \%$ & $2,63 \%$ & $4,38 \%$ & $1,05 \%$ & $0,86 \%$ & $3,13 \%$ & $0,82 \%$ & $1,45 \%$ \\
\hline mai.-19 & $0,54 \%$ & $0,76 \%$ & $1,32 \%$ & $2,39 \%$ & $2,49 \%$ & $4,00 \%$ & $0,86 \%$ & $2,24 \%$ & $0,49 \%$ & $1,84 \%$ \\
\hline jun.-19 & $0,47 \%$ & $3,76 \%$ & $3,77 \%$ & $3,83 \%$ & $2,66 \%$ & $3,86 \%$ & $4,73 \%$ & $3,13 \%$ & $4,13 \%$ & $7,02 \%$ \\
\hline jul.-19 & $0,57 \%$ & $0,90 \%$ & $1,33 \%$ & $2,20 \%$ & $-0,98 \%$ & $-1,47 \%$ & $1,16 \%$ & $4,24 \%$ & $0,55 \%$ & $6,42 \%$ \\
\hline ago.-19 & $0,50 \%$ & $-0,38 \%$ & $-0,12 \%$ & $2,60 \%$ & $0,17 \%$ & $1,08 \%$ & $0,27 \%$ & $1,60 \%$ & $-1,05 \%$ & $1,13 \%$ \\
\hline set.-19 & $0,46 \%$ & $3,48 \%$ & $3,22 \%$ & $1,58 \%$ & $3,86 \%$ & $2,31 \%$ & $3,34 \%$ & $2,49 \%$ & $4,52 \%$ & $1,17 \%$ \\
\hline out.-19 & $0,48 \%$ & $2,20 \%$ & $1,59 \%$ & $1,35 \%$ & $2,59 \%$ & $4,15 \%$ & $2,41 \%$ & $-0,70 \%$ & $1,32 \%$ & $2,46 \%$ \\
\hline nov.-19 & $0,38 \%$ & $1,08 \%$ & $0,93 \%$ & $2,33 \%$ & $-0,11 \%$ & $-2,43 \%$ & $1,10 \%$ & $5,00 \%$ & $0,84 \%$ & $4,87 \%$ \\
\hline dez.-19 & $0,37 \%$ & $6,59 \%$ & $7,94 \%$ & $10,58 \%$ & $6,71 \%$ & $5,84 \%$ & $7,62 \%$ & $11,38 \%$ & $6,70 \%$ & $12,57 \%$ \\
\hline jan.-20 & $0,38 \%$ & $-2,09 \%$ & $-1,51 \%$ & $-2,16 \%$ & $-2,17 \%$ & $-3,40 \%$ & $-0,95 \%$ & $0,36 \%$ & $-1,90 \%$ & $0,34 \%$ \\
\hline fev.-20 & $0,29 \%$ & $-7,62 \%$ & $-9,24 \%$ & $-6,47 \%$ & $-7,98 \%$ & $-5,38 \%$ & $-8,61 \%$ & $-6,80 \%$ & $-8,12 \%$ & $-8,04 \%$ \\
\hline mar.-20 & $0,34 \%$ & $-31,06 \%$ & $-28,80 \%$ & $-25,50 \%$ & $-29,45 \%$ & $-33,12 \%$ & $-28,41 \%$ & $-29,84 \%$ & $-30,68 \%$ & $-37,48 \%$ \\
\hline abr.-20 & $0,28 \%$ & $11,33 \%$ & $9,67 \%$ & $5,21 \%$ & $10,57 \%$ & $4,06 \%$ & $7,78 \%$ & $13,33 \%$ & $10,40 \%$ & $14,88 \%$ \\
\hline mai.-20 & $0,24 \%$ & $8,99 \%$ & $8,30 \%$ & $4,99 \%$ & $6,47 \%$ & $3,94 \%$ & $8,66 \%$ & $7,18 \%$ & $9,06 \%$ & $4,68 \%$ \\
\hline jun.-20 & $0,21 \%$ & $8,88 \%$ & $9,73 \%$ & $8,52 \%$ & $9,45 \%$ & $13,11 \%$ & $9,67 \%$ & $8,11 \%$ & $10,88 \%$ & $13,89 \%$ \\
\hline jul.-20 & $0,19 \%$ & $8,37 \%$ & 7,55\% & $5,99 \%$ & $9,52 \%$ & $9,78 \%$ & $8,27 \%$ & $9,65 \%$ & $6,95 \%$ & $9,46 \%$ \\
\hline
\end{tabular}




\begin{tabular}{|c|c|c|c|l|l|l|l|l|l|l|} 
ago.-20 & $0,16 \%$ & $-3,62 \%$ & $-3,45 \%$ & $-4,15 \%$ & $-4,72 \%$ & $-8,34 \%$ & $-2,69 \%$ & $-2,62 \%$ & $-3,50 \%$ & $-1,69 \%$ \\
\hline set.-20 & $0,16 \%$ & $-4,86 \%$ & $-3,95 \%$ & $-4,85 \%$ & $-6,02 \%$ & $-5,98 \%$ & $-5,57 \%$ & $-6,32 \%$ & $-4,73 \%$ & $-4,87 \%$ \\
\hline out.-20 & $0,16 \%$ & $-0,43 \%$ & $-1,00 \%$ & $0,00 \%$ & $-1,91 \%$ & $-1,02 \%$ & $-1,05 \%$ & $-1,03 \%$ & $-0,53 \%$ & $-2,31 \%$ \\
\hline nov.-20 & $0,15 \%$ & $15,82 \%$ & $16,11 \%$ & $14,75 \%$ & $14,83 \%$ & $17,93 \%$ & $15,79 \%$ & $9,24 \%$ & $16,26 \%$ & $17,53 \%$ \\
\hline dez.-20 & $0,16 \%$ & $9,19 \%$ & $9,00 \%$ & $9,08 \%$ & $8,74 \%$ & $12,12 \%$ & $9,14 \%$ & $7,14 \%$ & $9,41 \%$ & $6,79 \%$ \\
\hline jan.-21 & $0,15 \%$ & $-3,57 \%$ & $-2,93 \%$ & $-5,27 \%$ & $-4,88 \%$ & $-6,07 \%$ & $-3,60 \%$ & $-3,95 \%$ & $-2,70 \%$ & $-3,92 \%$ \\
\hline fev.-21 & $0,13 \%$ & $-4,50 \%$ & $-3,72 \%$ & $-5,07 \%$ & $-5,74 \%$ & $-7,37 \%$ & $-2,80 \%$ & $-4,14 \%$ & $-3,77 \%$ & $-2,18 \%$ \\
\hline mar.-21 & $0,20 \%$ & $6,09 \%$ & $6,35 \%$ & $7,36 \%$ & $5,20 \%$ & $6,30 \%$ & $5,79 \%$ & $3,92 \%$ & $6,00 \%$ & $5,50 \%$ \\
\hline abr.-21 & $0,21 \%$ & $2,12 \%$ & $2,99 \%$ & $2,89 \%$ & $-0,21 \%$ & $1,13 \%$ & $3,17 \%$ & $-1,06 \%$ & $2,84 \%$ & $4,73 \%$ \\
\hline mai.-21 & $0,21 \%$ & $5,99 \%$ & $5,26 \%$ & $4,75 \%$ & $4,95 \%$ & $6,93 \%$ & $5,42 \%$ & $5,49 \%$ & $6,24 \%$ & $6,31 \%$ \\
\hline & & & & & & & & & & \\
\hline $\begin{array}{l}\text { Retorno } \\
\text { (média) }\end{array}$ & $0,68 \%$ & $0,94 \%$ & $1,11 \%$ & $0,96 \%$ & $0,95 \%$ & $1,44 \%$ & $1,17 \%$ & $0,72 \%$ & $1,10 \%$ & $0,95 \%$ \\
\hline $\begin{array}{l}\text { Risco } \\
\text { (desvio } \\
\text { padrão) }\end{array}$ & $0,31 \%$ & $6,77 \%$ & $6,45 \%$ & $7,15 \%$ & $6,67 \%$ & $8,22 \%$ & $6,44 \%$ & $5,77 \%$ & $6,67 \%$ & $7,10 \%$ \\
\hline Variância & $0,001 \%$ & $0,458 \%$ & $0,417 \%$ & $0,512 \%$ & $0,445 \%$ & $0,676 \%$ & $0,415 \%$ & $0,332 \%$ & $0,444 \%$ & $0,504 \%$ \\
\hline $\begin{array}{l}\text { Índice de } \\
\text { Sharpe }\end{array}$ & $\mathbf{0 , 0 0 0 0 0}$ & $\mathbf{0 , 0 3 8 6 7}$ & $\mathbf{0 , 0 6 6 4 6}$ & $\mathbf{0 , 0 3 8 5 8}$ & $\mathbf{0 , 0 4 0 7 6}$ & $\mathbf{0 , 0 9 2 4 7}$ & $\mathbf{0 , 0 7 5 5 6}$ & $\mathbf{0 , 0 0 6 3 9}$ & $\mathbf{0 , 0 6 3 0 4}$ & $\mathbf{0 , 0 3 7 9 3}$ \\
\hline
\end{tabular}

Anexo II

\begin{tabular}{|c|c|c|}
\hline Código & Ação & Participação no lbovespa (\%) \\
\hline ABEV3 & AMBEV S/A & 3,575 \\
\hline ASAI3 & ASSAI & 0,318 \\
\hline AZUL4 & AZUL & 0,662 \\
\hline BTOW3 & B2W DIGITAL & 0,567 \\
\hline B3SA3 & B3 & 4,263 \\
\hline BIDI11 & BANCO INTER & 0,65 \\
\hline BBSE3 & BBSEGURIDADE & 0,693 \\
\hline BRML3 & BR MALLS PAR & 0,414 \\
\hline BBDC3 & BRADESCO & 1,276 \\
\hline BBDC4 & BRADESCO & 5,087 \\
\hline BRAP4 & BRADESPAR & 0,664 \\
\hline BBAS3 & BRASIL & 1,94 \\
\hline BRKM5 & BRASKEM & 0,641 \\
\hline BRFS3 & BRF SA & 0,947 \\
\hline BPAC11 & BTGP BANCO & 1,218 \\
\hline CRFB3 & CARREFOUR BR & 0,38 \\
\hline
\end{tabular}




\begin{tabular}{|c|c|c|}
\hline CCRO3 & CCR SA & 0,654 \\
\hline CMIG4 & CEMIG & 0,632 \\
\hline HGTX3 & CIA HERING & 0,18 \\
\hline CIEL3 & CIELO & 0,194 \\
\hline COGN3 & COGNA ON & 0,353 \\
\hline CPLE6 & COPEL & 0,15 \\
\hline CSAN3 & COSAN & 1,233 \\
\hline CPFE3 & CPFL ENERGIA & 0,232 \\
\hline CVCB3 & CVC BRASIL & 0,233 \\
\hline CYRE3 & CYRELA REALT & 0,305 \\
\hline ECOR3 & ECORODOVIAS & 0,096 \\
\hline ELET3 & ELETROBRAS & 0,688 \\
\hline ELET6 & ELETROBRAS & 0,462 \\
\hline EMBR3 & EMBRAER & 0,541 \\
\hline ENBR3 & ENERGIAS BR & 0,184 \\
\hline ENGI11 & ENERGISA & 0,514 \\
\hline ENEV3 & ENEVA & 0,913 \\
\hline EGIE3 & ENGIE BRASIL & 0,442 \\
\hline EQTL3 & EQUATORIAL & 1,051 \\
\hline EZTC3 & EZTEC & 0,138 \\
\hline FLRY3 & FLEURY & 0,352 \\
\hline GGBR4 & GERDAU & 1,357 \\
\hline GOAU4 & GERDAU MET & 0,426 \\
\hline GOLL4 & GOL & 0,208 \\
\hline NTCO3 & GRUPO NATURA & 2,021 \\
\hline HAPV3 & HAPVIDA & 0,838 \\
\hline HYPE3 & HYPERA & 0,615 \\
\hline IGTA3 & IGUATEMI & 0,158 \\
\hline GNDI3 & INTERMEDICA & 2,189 \\
\hline IRBR3 & IRBBRASIL RE & 0,325 \\
\hline ITSA4 & ITAUSA & 2,298 \\
\hline ITUB4 & ITAUUNIBANCO & 6,74 \\
\hline JBSS3 & JBS & 1,741 \\
\hline JHSF3 & JHSF PART & 0,095 \\
\hline KLBN11 & KLABIN S/A & 1,006 \\
\hline RENT3 & LOCALIZA & 1,653 \\
\hline LCAM3 & LOCAMERICA & 0,391 \\
\hline LWSA3 & LOCAWEB & 0,448 \\
\hline
\end{tabular}




\begin{tabular}{|c|c|c|}
\hline LAME4 & LOJAS AMERIC & 0,802 \\
\hline LREN3 & LOJAS RENNER & 1,806 \\
\hline MGLU3 & MAGAZ LUIZA & 2,298 \\
\hline MRFG3 & MARFRIG & 0,289 \\
\hline BEEF3 & MINERVA & 0,103 \\
\hline MRVE3 & MRV & 0,219 \\
\hline MULT3 & MULTIPLAN & 0,276 \\
\hline PCAR3 & P.ACUCAR-CBD & 0,262 \\
\hline PETR3 & PETROBRAS & 4,539 \\
\hline PETR4 & PETROBRAS & 5,559 \\
\hline BRDT3 & PETROBRAS BR & 1,368 \\
\hline PRIO3 & PETRORIO & 0,652 \\
\hline QUAL3 & QUALICORP & 0,345 \\
\hline RADL3 & RAIADROGASIL & 1,272 \\
\hline RAIL3 & RUMO S.A. & 1,077 \\
\hline SBSP3 & SABESP & 0,55 \\
\hline SANB11 & SANTANDER BR & 0,682 \\
\hline CSNA3 & SID NACIONAL & 1,222 \\
\hline SULA11 & SUL AMERICA & 0,41 \\
\hline SUZB3 & SUZANO S.A. & 1,838 \\
\hline TAEE11 & TAESA & 0,371 \\
\hline VIVT3 & TELEF BRASIL & 0,865 \\
\hline TIMS3 & TIM & 0,437 \\
\hline TOTS3 & TOTVS & 0,718 \\
\hline UGPA3 & ULTRAPAR & 0,95 \\
\hline USIM5 & USIMINAS & 0,412 \\
\hline VALE3 & VALE & 11,71 \\
\hline VVAR3 & VIAVAREJO & 1,022 \\
\hline WEGE3 & WEG & 2,157 \\
\hline YDUQ3 & YDUQS PART & 0,438 \\
\hline
\end{tabular}

Fonte: B3 
Anexo III

\begin{tabular}{|c|c|c|c|c|}
\hline Pricing Date & CDI & VALE3 & ITUB4 & COGN3 \\
\hline \multicolumn{5}{|l|}{ dez.-12 } \\
\hline jan.-13 & $0,59 \%$ & $-4,78 \%$ & $2,87 \%$ & $5,75 \%$ \\
\hline fev.-13 & $0,48 \%$ & $-6,10 \%$ & $2,21 \%$ & $5,83 \%$ \\
\hline mar.-13 & $0,54 \%$ & $-7,68 \%$ & $3,77 \%$ & $0,92 \%$ \\
\hline abr.-13 & $0,60 \%$ & $0,78 \%$ & $-6,44 \%$ & $8,18 \%$ \\
\hline mai.-13 & $0,58 \%$ & $-11,06 \%$ & $5,92 \%$ & $12,94 \%$ \\
\hline jun.-13 & $0,59 \%$ & $-4,46 \%$ & $-11,17 \%$ & $-1,79 \%$ \\
\hline jul.-13 & $0,71 \%$ & $6,62 \%$ & $1,34 \%$ & $5,15 \%$ \\
\hline ago.-13 & $0,70 \%$ & $10,94 \%$ & $0,61 \%$ & $-1,30 \%$ \\
\hline set.-13 & $0,70 \%$ & $0,12 \%$ & $8,49 \%$ & $-1,46 \%$ \\
\hline out.-13 & $0,80 \%$ & $6,55 \%$ & $10,07 \%$ & $5,04 \%$ \\
\hline nov.-13 & $0,71 \%$ & $0,36 \%$ & $-4,74 \%$ & $19,75 \%$ \\
\hline dez.-13 & $0,78 \%$ & $-0,47 \%$ & $-4,18 \%$ & $-0,71 \%$ \\
\hline jan.-14 & $0,84 \%$ & $-7,45 \%$ & $-3,43 \%$ & $-6,05 \%$ \\
\hline fev.-14 & $0,78 \%$ & $-0,16 \%$ & $5,00 \%$ & $18,56 \%$ \\
\hline mar.-14 & $0,76 \%$ & $-4,79 \%$ & $8,60 \%$ & $14,38 \%$ \\
\hline abr.-14 & $0,82 \%$ & $-3,76 \%$ & $8,59 \%$ & $-4,28 \%$ \\
\hline mai.-14 & $0,86 \%$ & $-3,40 \%$ & $-5,12 \%$ & $19,65 \%$ \\
\hline jun.-14 & $0,82 \%$ & $2,95 \%$ & $0,82 \%$ & $8,94 \%$ \\
\hline jul.-14 & $0,94 \%$ & $11,29 \%$ & $9,81 \%$ & $0,45 \%$ \\
\hline ago.-14 & $0,86 \%$ & $-10,53 \%$ & $16,17 \%$ & $10,92 \%$ \\
\hline set.-14 & $0,90 \%$ & $-7,77 \%$ & $-16,08 \%$ & $-8,24 \%$ \\
\hline out.-14 & $0,94 \%$ & $-3,40 \%$ & $8,56 \%$ & $14,82 \%$ \\
\hline nov.-14 & $0,84 \%$ & $-6,80 \%$ & $5,09 \%$ & $1,53 \%$ \\
\hline dez.-14 & $0,96 \%$ & $-6,00 \%$ & $-10,36 \%$ & $-13,53 \%$ \\
\hline jan.-15 & $0,93 \%$ & $-15,07 \%$ & $-4,81 \%$ & $-20,64 \%$ \\
\hline fev.-15 & $0,82 \%$ & $14,18 \%$ & $13,70 \%$ & $-15,51 \%$ \\
\hline mar.-15 & $1,04 \%$ & $-15,54 \%$ & $-3,22 \%$ & $-0,97 \%$ \\
\hline abr.-15 & $0,95 \%$ & $27,54 \%$ & $9,19 \%$ & $6,87 \%$ \\
\hline mai.-15 & $0,98 \%$ & $-11,48 \%$ & $-10,88 \%$ & $4,39 \%$ \\
\hline jun.-15 & $1,07 \%$ & $-8,74 \%$ & $-0,29 \%$ & $4,01 \%$ \\
\hline jul.-15 & $1,18 \%$ & $-2,35 \%$ & $-3,28 \%$ & $-19,27 \%$ \\
\hline ago.-15 & $1,11 \%$ & $0,33 \%$ & $-10,55 \%$ & $-8,96 \%$ \\
\hline set.-15 & $1,11 \%$ & $-7,52 \%$ & $-0,08 \%$ & $-11,13 \%$ \\
\hline out.-15 & $1,11 \%$ & $4,96 \%$ & $-0,08 \%$ & $27,77 \%$ \\
\hline nov.-15 & $1,06 \%$ & $-22,76 \%$ & $5,06 \%$ & $-5,74 \%$ \\
\hline dez.-15 & $1,16 \%$ & $-1,06 \%$ & $-4,58 \%$ & $2,99 \%$ \\
\hline jan.-16 & $1,05 \%$ & $-25,47 \%$ & $-5,13 \%$ & $-10,79 \%$ \\
\hline
\end{tabular}




\begin{tabular}{|c|c|c|c|c|}
\hline fev.-16 & $1,00 \%$ & $21,54 \%$ & $4,61 \%$ & $17,30 \%$ \\
\hline mar.-16 & $1,16 \%$ & $28,32 \%$ & $22,99 \%$ & $15,63 \%$ \\
\hline abr.-16 & $1,05 \%$ & $29,94 \%$ & $5,31 \%$ & $11,51 \%$ \\
\hline mai.-16 & $1,11 \%$ & $-27,79 \%$ & $-11,53 \%$ & $-12,55 \%$ \\
\hline jun.-16 & $1,16 \%$ & $14,47 \%$ & $4,29 \%$ & $22,71 \%$ \\
\hline jul.-16 & $1,11 \%$ & $13,65 \%$ & $11,64 \%$ & $6,17 \%$ \\
\hline ago.-16 & $1,21 \%$ & $-8,41 \%$ & $7,31 \%$ & $-3,70 \%$ \\
\hline set.-16 & $1,11 \%$ & $5,11 \%$ & $-0,89 \%$ & $7,21 \%$ \\
\hline out.-16 & $1,05 \%$ & $24,03 \%$ & $18,95 \%$ & $7,46 \%$ \\
\hline nov.-16 & $1,04 \%$ & $27,05 \%$ & $-7,69 \%$ & $-8,64 \%$ \\
\hline dez.-16 & $1,04 \%$ & $-7,92 \%$ & $-2,99 \%$ & $-7,74 \%$ \\
\hline jan.-17 & $1,08 \%$ & $25,29 \%$ & $10,10 \%$ & $1,37 \%$ \\
\hline fev.-17 & $0,86 \%$ & $1,66 \%$ & $9,58 \%$ & $1,19 \%$ \\
\hline mar.-17 & $1,05 \%$ & $-8,95 \%$ & $-5,30 \%$ & $-2,28 \%$ \\
\hline abr.-17 & $0,79 \%$ & $-4,72 \%$ & $3,63 \%$ & $12,56 \%$ \\
\hline mai.-17 & $0,93 \%$ & $-1,06 \%$ & $-9,38 \%$ & $-2,29 \%$ \\
\hline jun.-17 & $0,81 \%$ & $6,71 \%$ & $3,40 \%$ & $2,56 \%$ \\
\hline jul.-17 & $0,80 \%$ & $7,95 \%$ & $1,57 \%$ & $1,43 \%$ \\
\hline ago.-17 & $0,80 \%$ & $12,07 \%$ & $9,26 \%$ & $20,06 \%$ \\
\hline set.-17 & $0,64 \%$ & $-9,14 \%$ & $7,47 \%$ & $11,55 \%$ \\
\hline out.-17 & $0,64 \%$ & $0,71 \%$ & $-2,97 \%$ & $-10,30 \%$ \\
\hline nov.-17 & $0,57 \%$ & $9,46 \%$ & $-1,79 \%$ & $1,35 \%$ \\
\hline dez.-17 & $0,54 \%$ & $15,81 \%$ & $3,56 \%$ & $1,50 \%$ \\
\hline jan.-18 & $0,58 \%$ & $2,96 \%$ & $22,78 \%$ & $-11,67 \%$ \\
\hline fev.-18 & $0,46 \%$ & $8,70 \%$ & $0,74 \%$ & $-4,58 \%$ \\
\hline mar.-18 & $0,53 \%$ & $-5,26 \%$ & $1,88 \%$ & $-11,76 \%$ \\
\hline abr.-18 & $0,52 \%$ & $15,33 \%$ & $-0,58 \%$ & $3,06 \%$ \\
\hline mai.-18 & $0,52 \%$ & $4,02 \%$ & $-15,71 \%$ & $-22,07 \%$ \\
\hline jun.-18 & $0,52 \%$ & $-2,06 \%$ & $-6,11 \%$ & $-13,82 \%$ \\
\hline jul.-18 & $0,54 \%$ & $10,58 \%$ & $11,57 \%$ & $21,35 \%$ \\
\hline ago.-18 & $0,57 \%$ & $0,60 \%$ & $-4,35 \%$ & $-8,57 \%$ \\
\hline set.-18 & $0,47 \%$ & $11,57 \%$ & $4,43 \%$ & $11,47 \%$ \\
\hline out.-18 & $0,54 \%$ & $-5,20 \%$ & $11,63 \%$ & $0,18 \%$ \\
\hline nov.-18 & $0,49 \%$ & $-6,90 \%$ & $9,76 \%$ & $-7,32 \%$ \\
\hline dez.-18 & $0,49 \%$ & $-3,40 \%$ & $-1,37 \%$ & $-15,51 \%$ \\
\hline jan.-19 & $0,54 \%$ & $-10,78 \%$ & $9,27 \%$ & $28,85 \%$ \\
\hline fev.-19 & $0,49 \%$ & $3,50 \%$ & $-4,59 \%$ & $-4,07 \%$ \\
\hline mar.-19 & $0,47 \%$ & $8,13 \%$ & $-2,22 \%$ & $-3,32 \%$ \\
\hline abr.-19 & $0,52 \%$ & $-1,62 \%$ & $-1,71 \%$ & $-7,82 \%$ \\
\hline mai.-19 & $0,54 \%$ & $-2,20 \%$ & $3,50 \%$ & $6,63 \%$ \\
\hline jun.-19 & $0,47 \%$ & $5,76 \%$ & $3,66 \%$ & $6,12 \%$ \\
\hline jul.-19 & $0,57 \%$ & $-3,88 \%$ & $-3,92 \%$ & $14,55 \%$ \\
\hline ago.-19 & $0,50 \%$ & $-8,52 \%$ & $-0,25 \%$ & $-19,49 \%$ \\
\hline
\end{tabular}




\begin{tabular}{|c|c|c|c|c|}
\hline set.-19 & $0,46 \%$ & $4,79 \%$ & $3,25 \%$ & $10,81 \%$ \\
\hline out.-19 & $0,48 \%$ & $-1,14 \%$ & $3,48 \%$ & $-13,43 \%$ \\
\hline nov.-19 & $0,38 \%$ & $5,89 \%$ & $-3,92 \%$ & $6,00 \%$ \\
\hline dez.-19 & $0,37 \%$ & $9,46 \%$ & $6,73 \%$ & $11,51 \%$ \\
\hline jan.-20 & $0,38 \%$ & $-5,69 \%$ & $-11,49 \%$ & $1,66 \%$ \\
\hline fev.-20 & $0,29 \%$ & $-11,85 \%$ & $0,52 \%$ & $-13,17 \%$ \\
\hline mar.-20 & $0,34 \%$ & $-2,45 \%$ & $-27,82 \%$ & $-60,36 \%$ \\
\hline abr.-20 & $0,28 \%$ & $3,78 \%$ & $-1,33 \%$ & $38,50 \%$ \\
\hline mai.-20 & $0,24 \%$ & $18,14 \%$ & $1,26 \%$ & $-5,05 \%$ \\
\hline jun.-20 & $0,21 \%$ & $5,52 \%$ & $10,53 \%$ & $25,67 \%$ \\
\hline jul.-20 & $0,19 \%$ & $8,55 \%$ & $5,75 \%$ & $25,26 \%$ \\
\hline ago.-20 & $0,16 \%$ & $-1,68 \%$ & $-12,21 \%$ & $-31,16 \%$ \\
\hline set.-20 & $0,16 \%$ & $3,18 \%$ & $-4,37 \%$ & $-9,12 \%$ \\
\hline out.-20 & $0,16 \%$ & $2,44 \%$ & $4,39 \%$ & $-17,18 \%$ \\
\hline nov.-20 & $0,15 \%$ & $28,82 \%$ & $21,74 \%$ & $9,32 \%$ \\
\hline dez.-20 & $0,16 \%$ & $12,12 \%$ & $10,98 \%$ & $-1,28 \%$ \\
\hline jan.-21 & $0,15 \%$ & $0,57 \%$ & $-10,21 \%$ & $-2,38 \%$ \\
\hline fev.-21 & $0,13 \%$ & $7,47 \%$ & $-9,26 \%$ & $-17,26 \%$ \\
\hline mar.-21 & $0,20 \%$ & $3,65 \%$ & $9,74 \%$ & $6,42 \%$ \\
\hline abr.-21 & $0,21 \%$ & $11,28 \%$ & $-1,33 \%$ & $-2,76 \%$ \\
\hline mai.-21 & $0,21 \%$ & $5,28 \%$ & $7,54 \%$ & $9,04 \%$ \\
\hline Retorno & $0,68 \%$ & $1,91 \%$ & $1,43 \%$ & $0,95 \%$ \\
\hline Risco & $0,31 \%$ & $11,23 \%$ & $8,54 \%$ & $13,91 \%$ \\
\hline Variância & $0,001 \%$ & $1,261 \%$ & $0,730 \%$ & $1,935 \%$ \\
\hline Índice Sharpe & 0,00000 & 0,10971 & 0,08820 & 0,01916 \\
\hline
\end{tabular}

